\title{
Comprehensive Summary Supporting Clinical Investigation of GS-441524 for Covid-19 Treatment
}

\author{
Victoria C. Yan \& Florian L. Muller \\ Department of Cancer Systems Imaging, University of Texas MD Anderson Cancer Center, Houston, TX, USA \\ The authors declare no competing financial interests. Last updated: 08/29/2020
}

1. Glossary 2

2. Overview of SARS-CoV-2 pathology 3

3. Overview of remdesivir 3

4. Limitations of remdesivir for Covid-19 treatment

4.1 Synthesis, large-scale manufacturing, and distribution challenges 4

4.2 Remdesivir is unstable in blood, subject to hepatic extraction and 5 toxic to the liver

4.2.1 Remdesivir is poorly suited for delivery of active drug to cells 11

critical in the pathogenesis of Covid-19

4.3 Administration of remdesivir requires complex excipients associated 14

with nephrotoxicity

5. Advantages of GS-441524 for Covid-19 treatment

5.1 Simple synthesis, advantageous physiochemical properties, and

implications thereof

5.2 In vitro data demonstrating similar or superior potency in SARS-CoV-

2-infected cells

5.3 GS-441524 is not hepatotoxic and well-suited for pneumocyte-

targeted delivery

5.4 In vivo data demonstrating exceptional safety and efficacy against a related coronavirus

5.5 Potential to be administered as a prophylactic

6. Summary

7. Frequently asked questions (FAQ)

8. References 


\section{Glossary}

SARS-CoV-2

Phosphate

Prodrug

McGuigan prodrug

Stereocenter

Nucleotide [analogue]

Nucleoside [analogue]

Pneumocytes

Hepatic extraction

$\mathrm{EC}_{50}$

Feline infectious peritonitis
A type of beta coronavirus that causes Covid-19

A chemical group of oxygen and phosphorus found on many metabolites such as nucleotides. Phosphatecontaining drugs are negatively charged at physiological $\mathrm{pH}$ and cannot easily diffuse through cell membranes.

A drug that is inactive when given but is converted to its active form through a series of (often enzymatic) steps. Remdesivir and GS-441524 are both prodrugs.

A specific type of phosphate prodrug in which the phosphate is protected by a phenol and an L-alanine ester.

An atom that is bonded to unique substituents (no two attachments are the same) that are oriented in a precise configuration.

Characterized by the presence of a nitrogenous base, (deoxy)ribose sugar, and phosphate(s). Example: adenosine monophosphate (AMP). Remdesivir is a nucleotide analogue.

Characterized by the presence of a nitrogenous base and (deoxy)ribose sugar. Example: adenosine. GS-441524 is a nucleoside analogue.

Also known as type I/type II alveolar cells (AT1/AT2). Main site of infection for SARS-CoV-2.

Drug removal from venous blood by passage through the liver

Concentration of drug required to inhibit viral replication by $50 \%$

A disease in cats caused by a feline coronavirus 


\section{Overview of SARS-CoV-2 pathology}

Covid-19 is caused by a beta coronavirus called severe acute respiratory syndrome coronavirus 2 (SARS-CoV-2) ${ }^{1,2}$. The disease typically manifests first as an upper respiratory tract infection with fever, cough, sore throat, shortness of breath being typical symptoms. While most cases are mild, severe cases can progress to pneumonia and acute severe respiratory distress syndrome (ARDS), a complex pathology involving diffuse alveolar damage, and inflammation ${ }^{1,3,4}$. SARS-CoV-2 gains entry into cells via the ACE2 protein ${ }^{5}$ on cell surfaces and as a result, preferentially infects type II alveolar pneumocytes, which express the highest levels of ACE2 of all cells in the lungs ${ }^{1}$. Type II alveolar pneumocytes are thus the critical site for viral replication ${ }^{1,3}$. The normal function of these cells is to produce lung surfactant; the absence of this surfactant results in the alveolus filling with fluid. Viral particles can shed from infected pneumocytes which activates a strong inflammatory response. Ultimately, these pathologies prevent lungs from exchanging oxygen with $\mathrm{CO}_{2}$, requiring respiratory support therapy, and in severe cases, death ${ }^{1}$. While there are important extrapulmonary manifestations of SARS-CoV-2 infection ${ }^{6}$, the common feature of severe Covid-19 is ARDS and replication of SARS-CoV-2 in type II pneumocytes is a critical component of its pathogenesis ${ }^{1}$. Inhibiting viral replication in type II pneumocytes is thus a critical focus of antiviral therapies.

\section{Overview of remdesivir}

Remdesivir (RDV; GS-5734) is an antiviral nucleotide analogue prodrug developed by Gilead Sciences. Originally developed by Gilead for the treatment of hepatitis ${ }^{7}$, RDV has shown broadspectrum activity against Ebola virus ${ }^{8,9}$, SARS-CoV, and now SARS-CoV-2 ${ }^{10,11}$, among others ${ }^{12}$. It is currently (08/29/2020) one of two drugs that have shown efficacy for treating Covid-19 in clinical trials $^{13}$. Initial reports on the efficacy of RDV for Covid- 19 have been modest ${ }^{13}$, at best, and ineffective at worst ${ }^{14}$. These clinical results contrast the breadth of pre-clinical data, which have demonstrated strong antiviral activity when RDV is administered during early infection ${ }^{11,15}$ and even stronger antiviral activity when administered prophylactically ${ }^{15,16}$. Dr. Eric Topol best summarized this disparity, saying "It [RDV] was expected to have a whopping effect...It clearly does not have that." Fundamental structural features of RDV preclude administration as a prophylactic and likely subvert its activity as a therapeutic. RDV is preferentially metabolized by tissues such as the liver (described in Section 4.3, 4.4), making oral administration unfeasible. Among the population of cells in the lung, RDV is likely metabolized preferentially by alveolar macrophages, rather than type II pneumocytes (main site of SARS-CoV-2 replication; described in Section 4.3, 4.4). This document provides evidence that administration of the RDV parent nucleoside, GS-441524, could overcome these limitations and is the more suitable Covid-19 treatment that could be administered either prophylactically or therapeutically. 


\section{Limitations of remdesivir for Covid-19 treatment}

\section{Key points:}

- Difficult to synthesize ${ }^{17}$, which hampers large-scale production and distribution ${ }^{20,63}$

- Poor stability in human blood, resulting in rapid conversion to the non-permeable alanyl-metabolite, then to the parent nucleoside, GS-44152426,29

- High liver extraction/bioactivation is associated with hepatotoxicity which precludes oral dosing and minimizes delivery of bioactive drug to Covid-19-critical cell types ${ }^{32}$

- Poor water solubility requires dissolution in a complex drug vehicle that is nephrotoxic at high or extended doses $13,29,43$

\subsection{Synthesis, large-scale manufacturing, and distribution challenges}

Scheme 2. Second Generation Synthesis of $4 b^{a}$

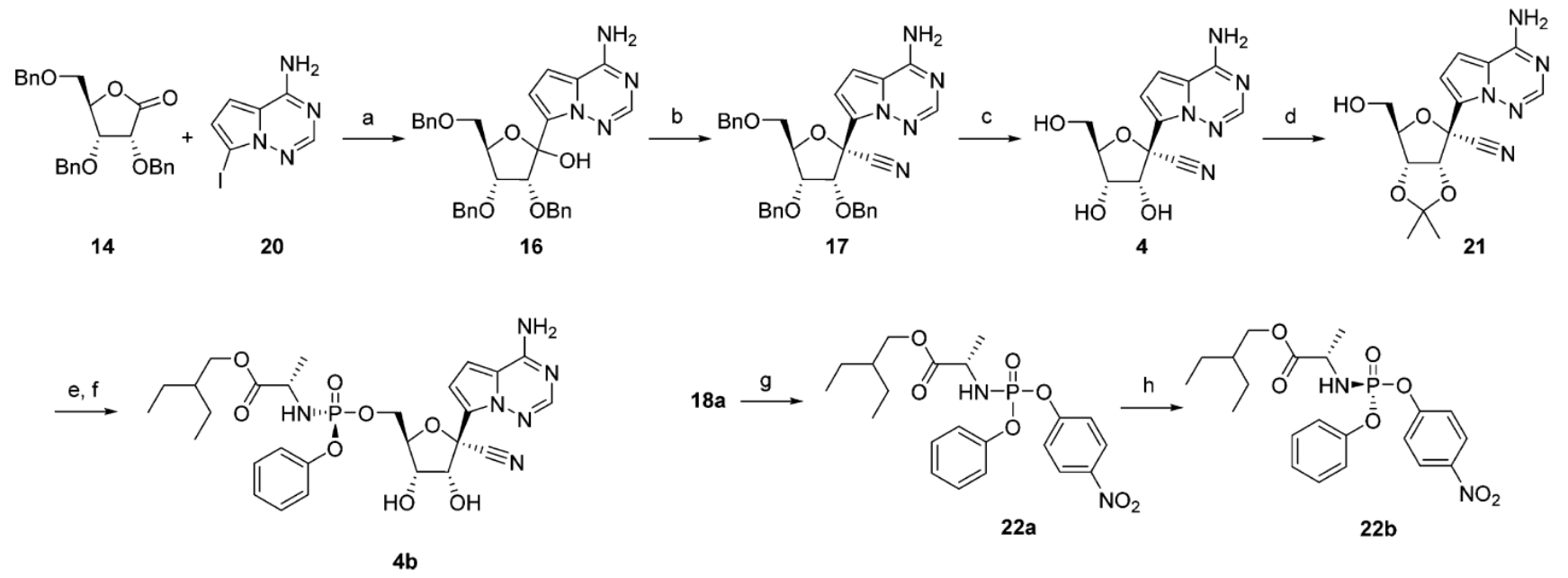

${ }^{a}$ Reagents and conditions: (a) TMSCl, PhMgCl, $i$-PrMgCl-LiCl, THF, $-20{ }^{\circ} \mathrm{C}, 40 \%$; (b) TMSCN, TfOH, TMSOTf, $\mathrm{CH}_{2} \mathrm{Cl}_{2},-78{ }^{\circ} \mathrm{C}, 85 \%$; $(\mathrm{c})$ $\mathrm{BCl}_{3}, \mathrm{CH}_{2} \mathrm{Cl}_{2},-20^{\circ} \mathrm{C}$, 86\%; (d) 2,2-dimethoxypropane, $\mathrm{H}_{2} \mathrm{SO}_{4}$, acetone, rt, $90 \%$; (e) 22b, $\mathrm{MgCl}_{2},(i-\mathrm{Pr})_{2} \mathrm{NEt}, \mathrm{MeCN}, 50{ }^{\circ} \mathrm{C}, 70 \%$; (f) $37 \% \mathrm{HCl}$, THF, rt, 69\%; (g) OP(OPh) $\mathrm{Cl}_{2}, \mathrm{Et}_{3} \mathrm{~N}, \mathrm{CH}_{2} \mathrm{Cl}_{2},-78{ }^{\circ} \mathrm{C}$, then 4-nitrophenol, $\mathrm{Et}_{3} \mathrm{~N}, 0{ }^{\circ} \mathrm{C}, 80 \%$; (h) $i-\mathrm{Pr}_{2} \mathrm{O}, 39 \%$.

Figure 1. Synthetic scheme of remdesivir (4b) from Scheme 2 in Siegel et al. J. Med. Chem. (2017)17.

RDV is a complex nucleotide analogue prodrug that contains 6 stereocenters and requires over 7 steps to synthesize (preparation of Figure 1, intermediate 207,18 requires additional steps not shown). Its synthetic difficulty can largely be attributed to its identity as a phosphate prodrug of the McGuigan class, as the RDV phosphate is protected by a phenol and an L-alanine ester ${ }^{17,19}$. In the synthesis of RDV described by Gilead scientists ${ }^{17}$ (Figure 1), it is apparent that the chemistry around the phosphate prodrug (Figure 1, steps d-h) account for 4 of the 7 synthetic steps (step d is included as a protecting step to enable efficient attachment of the phosphate prodrug onto the nucleoside). Step h, in particular, provides strong evidence of the difficulty of the RDV synthesis, 
demonstrating the precise stereochemical demands around the phosphorous atom to achieve the desired level of antiviral potency (39\% yield) ${ }^{17}$.

Since the beginning of the global pandemic, many chemists expressed their concerns over the complicated nature of the RDV synthesis ${ }^{20}$. Gilead has been well-aware of the limited supply of $\mathrm{RDV}^{21}$ and CEO Daniel O'Day publicly commented on the difficulty of the RDV synthesis in April ${ }^{22}$. The challenge of mass producing RDV ties directly to the global shortage of RDV 23 and patchy distribution to U.S. hospitals ${ }^{24}$. At the global scale, these matters are exacerbated by recent U.S. purchase of the world supply of RDV 25 .

\section{liver

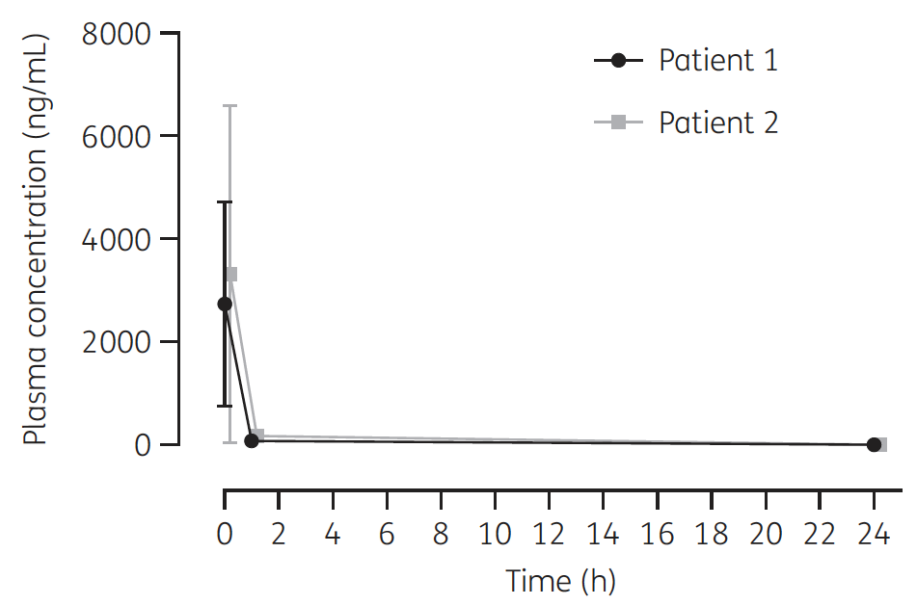

4.2 Remdesivir is unstable in blood, subject to hepatic extraction and is toxic to the

Figure 1. Pharmacokinetics of remdesivir following intravenous administration of multiple doses of remdesivir in critically ill patients (Patient 1 with renal impairment and Patient 2 without renal impairment; mean \pm SD measured 3-9 days after remdesivir initiation).

Figure 2. Half-life of RDV in SARS-CoV-2 infected patients following intravenous administration, as reported in Figure 1 of Tempestilli et al. J. Antimicrob. Chemother. (2020) ${ }^{26}$.

\begin{tabular}{|c|c|c|}
\hline Study & Species, dose & Half-life (h) \\
\hline Warren et al. Nature $(2016)^{9}$ & Rhesus monkey (10 mg/kg single dose) & 0.39 \\
\hline Sheahan et al. Sci. Transl. Med. (2017) ${ }^{16}$ & Ces1c/- mouse $(50 \mathrm{mg} / \mathrm{kg})$ & 0.4 \\
\hline Siegel et al. J. Med. Chem. (2017) ${ }^{17}$ & Rhesus monkey (10 mg/kg, single dose) & $\sim 0.4$ \\
\hline Williamson et al. Nature (2020) ${ }^{11}$ & $\begin{array}{l}\text { Rhesus monkey (10 mg/kg loading, } 5 \\
\mathrm{mg} / \mathrm{kg} \text { daily after) }\end{array}$ & 0.39 \\
\hline $\begin{array}{l}\text { Tempestilli et al. J. Antimicrob. } \\
\text { Chemother. }(2020)^{26}\end{array}$ & $\begin{array}{l}\text { Human (200 mg loading dose, } 100 \mathrm{mg} \\
\text { daily after) }\end{array}$ & $<<1^{*}$ \\
\hline
\end{tabular}




\begin{tabular}{|l|l|c|}
\hline $\begin{array}{l}\text { Humeniuk et al. Clin. Transl. Sci. } \\
(2020)^{27}\end{array}$ & Human (3-225 mg, single dose) & $\sim 1$ \\
\hline $\begin{array}{l}\text { Alvarez et al. Clin. Chem. Lab. Med. } \\
(2020)^{28}\end{array}$ & $\begin{array}{l}\text { Human (200 mg loading dose, } 100 \mathrm{mg} \\
\text { daily after) }\end{array}$ & 0.8 \\
\hline
\end{tabular}

Table 1. Summary of pharmacokinetic experiments with RDV across various species. *Half-life of RDV in SARS-CoV-2 patients is much less than $1 \mathrm{~h}$, see Figure 2.

Even before RDV was being trialed for Ebola virus ${ }^{29}$ and now for SARS-CoV-2, multiple pre-clinical

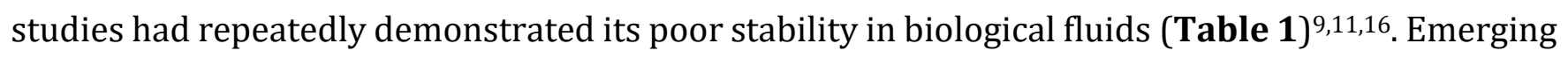
clinical trial data in Covid-19 patients treated with RDV concur with pre-clinical observations on the short plasma half-life of RDV. A recent report by Tempestilli and colleagues found that RDV was undetectable in human plasma 1 hour after administration ${ }^{26}$ (Figure 2, Table 1)

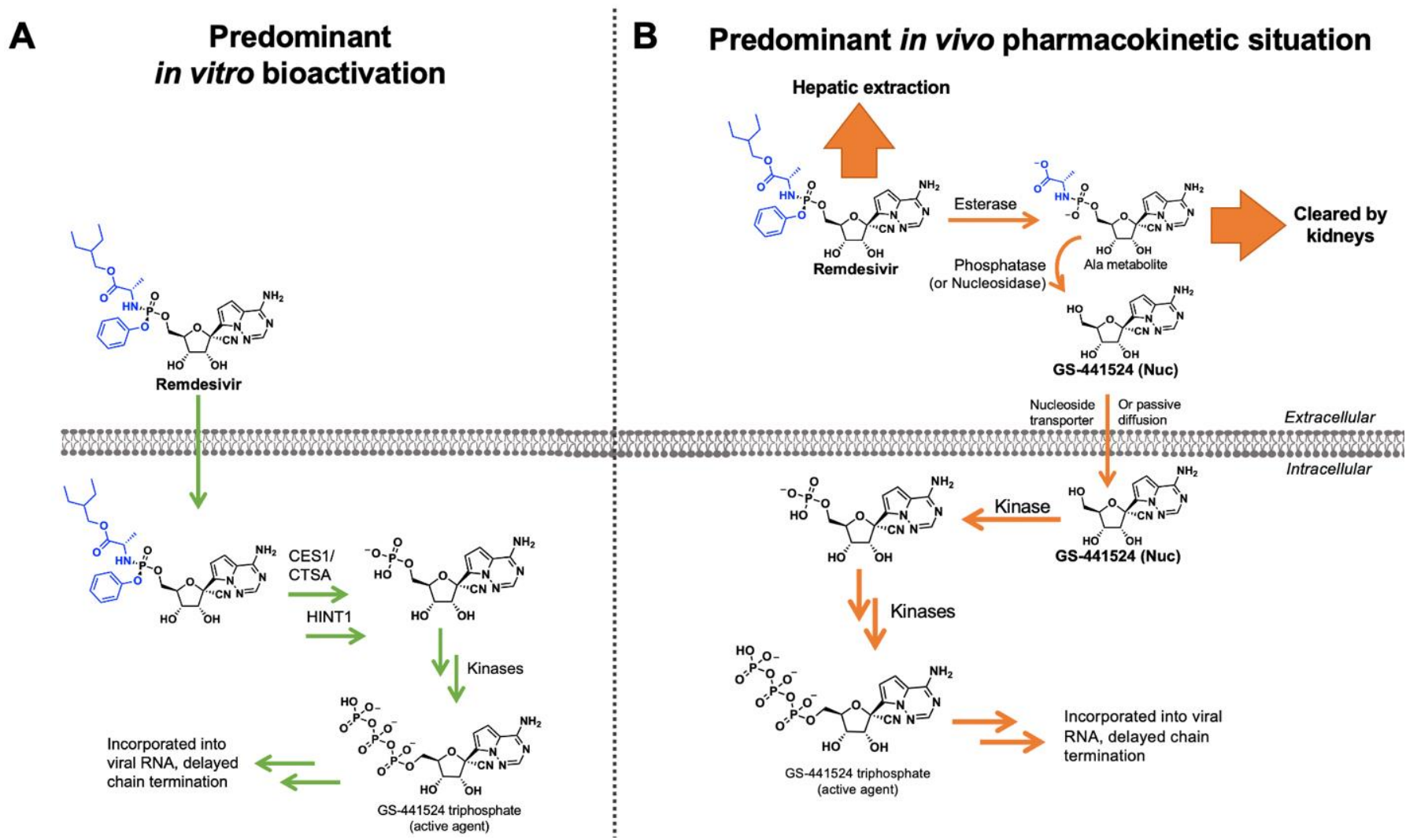

Figure 3. Schematic of ideal bioactivation mechanism for RDV, which predominately occurs in vitro (left) contrasted with the predominant pharmacokinetic situation in vivo (right). McGuigan prodrug moieties on $\mathrm{RDV}$ are indicated in blue.

RDV is designed to deliver a nucleotide monophosphate analogue intracellularly, which is then phosphorylated twice to yield the active nucleotide triphosphate (NTP) inhibitor (Figure 3) ${ }^{17,19}$. Monophosphate analogues are poorly cell permeable due their anionic character, which limits their passage across the cell membrane. Phosphate prodrugs, such as those of the McGuigan class, are designed to mask negative charges and increase the lipophilicity of the drug to enable passage into 
the cell. Once inside the cell, the phosphate prodrug would be cleaved by a series of (enzymatic) steps to reveal the nucleotide monophosphate analogue; this is then phosphorylated twice to yield the active NTP (Figure 3, left). The intracellular bioactivation of McGuigan prodrugs, including RDV, is carried out by enzymes that hydrolyze the phosphate prodrug moieties are: 1.) carboxylesterase 1 (CES1)/cathepsin A (CTSA) and 2.) phosphoramidase (HINT1) ${ }^{19,30,31}$. However, the prevalence of various esterases, phosphatases, and nucleosidases in plasma result in rapid, premature hydrolysis of the McGuigan prodrug moieties on RDV, to yield the intermediate Ala metabolite (GS-704277), a highly hydrophilic cell-impermeable species subject to renal clearance. Pre-clinical studies in rats suggest the Ala metabolite is nephrotoxic (European Medicines Agency (EMA) Summary on RDV29, page 25). Only a fraction that escapes conversion to the potentially toxic Ala metabolite is dephosphorylated to the parent nucleoside, GS-44152, which persists in plasma across all species examined $^{9,11,16,26,32}$ (Figure 3, right; Figure 4).

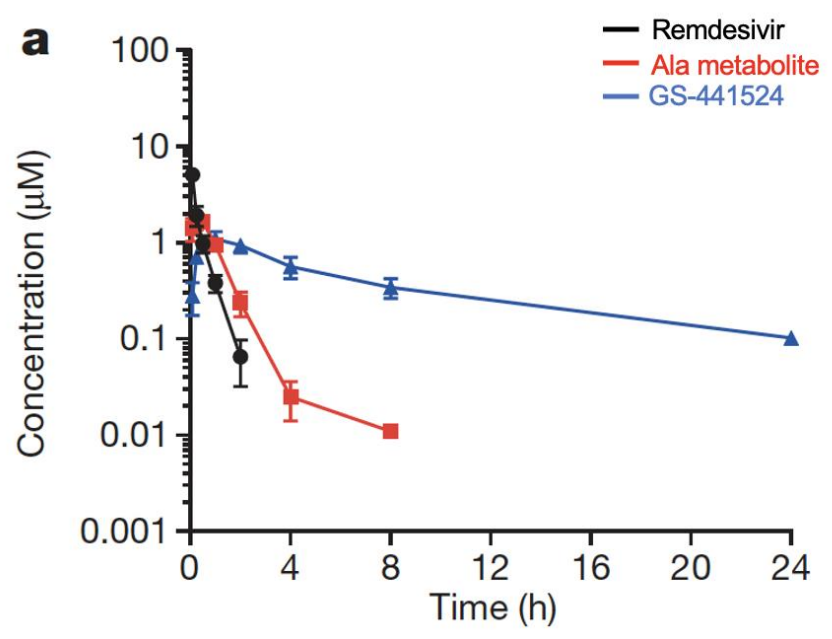

Figure 4. Plasma levels of RDV following intravenous injection $(10 \mathrm{mg} / \mathrm{kg})$ in healthy rhesus macaques, adapted from Figure 2a in Warren et al. Nature (2016). Rapid disappearance of RDV (black) is accompanied by rapid, sharp increases in the intermediate Ala metabolite (red) and GS-441524 (blue).

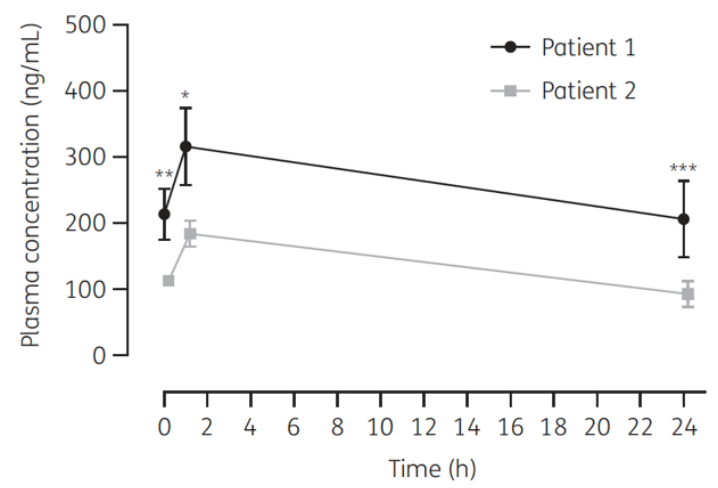

Figure 2. Pharmacokinetics of nucleoside analogue GS-441524 following intravenous administration of multiple doses of remdesivir in two critically ill patients (mean \pm SD measured 3-9 days after remdesivir initiation). Statistical comparison of GS-441524 plasma concentrations at pharmacokinetic timepoints in Patient 1 (with renal impairment) versus Patient 2 (without renal impairment): ${ }^{*} P<0.05$; ${ }^{* *} P<0.01$; ${ }^{* *} P<0.001$ (Mann-Whitney test; $P<0.05$ was considered significant). 
Figure 5. Plasma levels of GS-441524 in SARS-CoV-2 patients following intravenous injection of RDV, as reported in Figure 2 of Tempestilli et al. J. Antimicrob. Chemother. (2020) ${ }^{26}$. Unlike RDV, which disappears from plasma after $\sim 1$ hour $\left(\mathrm{t}_{1 / 2}<<1 \mathrm{~h}\right)$, GS-441524 persists in plasma for over 24 hours.

A phase I, dose-escalation study with RDV in healthy subjects recently published by Gilead researchers further demonstrated the exceedingly short half-life $\left(\mathrm{t}_{1 / 2} \sim 1 \mathrm{~h}\right)$ of $\mathrm{RDV}$ when administered IV over 30 minutes to 2 hours at all concentrations examined ( $3 \mathrm{mg}, 10 \mathrm{mg}, 30 \mathrm{mg}, 75$ $\mathrm{mg}, 150 \mathrm{mg}, 225 \mathrm{mg} 27$. RDV half-life was shorter at lower concentrations of drug administered 10 $\mathrm{mg}, \mathrm{t}_{1 / 2}=0.66 \mathrm{~h}$; no data for $3 \mathrm{mg}$ dose) and higher at higher concentrations of drug administered (225 mg, $\left.t_{1 / 2}=1.05 \mathrm{~h}\right)$. Similarly, the intermediate Ala metabolite exhibited a half-life of approximately 1.5 hours. GS-441524 persisted in plasma for at least 22 hours when RDV was dosed at $10 \mathrm{mg}$ or higher.

\begin{tabular}{|c|c|c|c|c|c|c|}
\hline $\begin{array}{l}\text { Parameter } \\
\text { (RDV solution; } \\
\text { 2-hour infusion) }\end{array}$ & $\begin{array}{c}\text { Cohort } 1 \\
3 \mathrm{mg} \\
N=8\end{array}$ & $\begin{array}{c}\text { Cohort } 2 \\
10 \mathrm{mg} \\
N=8\end{array}$ & $\begin{array}{c}\text { Cohort } 3 \\
30 \mathrm{mg} \\
N=8\end{array}$ & $\begin{array}{l}\text { Cohort } 4 \\
75 \mathrm{mg} \\
N=8\end{array}$ & $\begin{array}{c}\text { Cohort } 5 \\
150 \mathrm{mg} \\
N=8\end{array}$ & $\begin{array}{c}\text { Cohort } 6 \\
225 \mathrm{mg} \\
N=8\end{array}$ \\
\hline \multicolumn{7}{|l|}{ RDV } \\
\hline$A U C_{i n f}, h \cdot n g / m L$ & - & $230(28.4)^{\mathrm{a}}$ & 774 (22.9) & $2000(27.1)$ & $2980(19.0)$ & $5270(11.6)$ \\
\hline $\mathrm{AUC}_{\text {last }}, \mathrm{h}^{\bullet} \mathrm{ng} / \mathrm{mL}$ & $67.1(17.2)$ & $230(16.1)$ & 768 (23.2) & 1990 (27.3) & 2970 (19.1) & $5260(11.7)$ \\
\hline $\mathrm{C}_{\max }, \mathrm{ng} / \mathrm{mL}$ & $57.5(31.1)$ & $221(31.2)$ & 694 (18.6) & $1630(38.6)$ & $2280(30.1)$ & $4420(16.0)$ \\
\hline $\mathrm{T}_{\max }$, hours & $2.03(2.01-2.04)$ & $2.01(2.00-2.03)$ & $2.02(2.00-2.03)$ & $2.03(2.03-2.05)$ & $2.00(1.98-2.04)$ & $1.97(1.95-1.98)$ \\
\hline$t_{1 / 2}$, hours & - & $0.66(0.54,0.79)^{a}$ & $0.81(0.61,0.91)$ & $0.90(0.82,1.07)$ & $0.99(0.92,1.06)$ & $1.05(0.96,1.21)$ \\
\hline $\mathrm{CL}, \mathrm{mL} / \mathrm{min}$ & & $755(28.4)^{\mathrm{a}}$ & $700(39.4)$ & $661(23.5)$ & $863(16.6)$ & $719(11.7)$ \\
\hline$V_{z}, L$ & & $45.1(53.7)^{\mathrm{a}}$ & $48.8(54.0)$ & $56.3(42.3)$ & $73.4(16.4)$ & $66.5(17.2)$ \\
\hline $\mathrm{CL}_{\Gamma}, \mathrm{mL} / \min$ & & & $48.6(17.7)$ & $52.1(26.4)$ & $78.1(23.6)$ & $71.4(25.9)$ \\
\hline \multicolumn{7}{|l|}{ GS-441524 } \\
\hline$A U C_{i n f}, h^{\bullet} n g / m L$ & $55.2(27.6)^{b}$ & $264(26.7)$ & 1010 (31.1) & $2470(22.7)$ & 4640 (16.2) & $7350(20.7)$ \\
\hline $\mathrm{AUC}_{\text {last }}, \mathrm{h}^{\bullet} \mathrm{ng} / \mathrm{mL}$ & $19.3(24.8)$ & $181(35.7)$ & $893(33.9)$ & $2370(23.2)$ & $4520(16.4)$ & $7110(20.9)$ \\
\hline $\mathrm{C}_{\max }, \mathrm{ng} / \mathrm{mL}$ & $3.20(10.9)$ & $9.40(28.4)$ & $34.3(30.9)$ & $85.8(23.9)$ & $152(23.6)$ & 257 (30.2) \\
\hline $\mathrm{T}_{\max }$, hours & $5.00(4.00,5.00)$ & $3.57(3.00,5.00)$ & $4.00(3.25,4.00)$ & $4.50(3.50,5.00)$ & $4.00(3.50,4.00)$ & $3.50(3.00,4.00)$ \\
\hline$t_{1 / 2}$, hours & $12.9(7.35,14.2)^{b}$ & $22.0(19.8,25.3)$ & $27.3(22.7,29.6)$ & $26.9(25.4,28.9)$ & $27.4(25.9,28.8)$ & $30.6(29.5,31.1)$ \\
\hline $\mathrm{CL}_{\mathrm{r}}, \mathrm{mL} / \mathrm{min}$ & & & $116(9.85)$ & $117(23.4)$ & $127(12.5)$ & $136(17.7)$ \\
\hline \multicolumn{7}{|l|}{ GS-704277 } \\
\hline$A U C_{\text {inf }}, h^{\bullet} \mathrm{ng} / \mathrm{mL}$ & $11.1(28.9)^{\mathrm{c}}$ & $29.5(20.9)$ & $86.3(32.8)$ & $270(49.0)$ & $460(19.7)$ & $807(19.8)$ \\
\hline $\mathrm{AUC}_{\text {last }}, \mathrm{h}^{\bullet} \mathrm{ng} / \mathrm{mL}$ & $4.60(54.1)$ & $25.8(24.4)$ & $81.9(33.7)$ & 262.5 (49.9) & $453(20.0)$ & $800(19.8)$ \\
\hline $\mathrm{C}_{\max }, \mathrm{ng} / \mathrm{mL}$ & $3.40(21.1)$ & $11.8(22.6)$ & $33.7(31.4)$ & $101(57.9)$ & $171(22.3)$ & $315.1(19.5)$ \\
\hline $\mathrm{T}_{\max }$, hours & $2.25(2.03,2.25)$ & $2.01(2.00,2.03)$ & $2.02(2.00,2.03)$ & $2.04(2.03,2.15)$ & $1.98(1.98,2.18)$ & $1.97(1.96,1.98)$ \\
\hline$t_{1 / 2}$, hours & $1.09(0.72,2.07)^{c}$ & $0.87(0.85,1.01)$ & $1.09(0.94,1.18)$ & $1.48(1.29,2.07)$ & $1.81(1.65,1.91)$ & $1.77(1.39,1.90)$ \\
\hline
\end{tabular}

Subjects received RDV solution i.v. formulation administered as a 2-hour infusion. All pharmacokinetic parameters are reported as mean (\% coefficient of variation), except for $\mathrm{T}_{\max }$ and $\mathrm{t}_{1 / 2}$, which are reported as median (Q1, Q3). Plasma $\mathrm{AUC}_{\text {inf }}$ and $\mathrm{t}_{1 / 2}$ were not estimable for RDV in cohort 1.

$\mathrm{AUC}_{\text {inf, }}$, area under the curve vs. time curve extrapolated to infinity; $\mathrm{AUC}_{\text {last, }}$, area under the curve from time zero to the last quantifiable concentration; CL, clearance; $\mathrm{CL}_{\Gamma}$, renal clearance; $\mathrm{C}_{\max }$, peak plasma concentration; RDV, remdesivir; $\mathrm{t}_{1 / 2}$, terminal half-life; $\mathrm{T}_{\max }$, time to peak concentration; $\mathrm{V}_{\mathrm{z}}$, volume of distribution. ${ }^{a}$ Two for $\mathrm{AUC}_{\text {inf }}, \mathrm{t}_{1 / 2}, \mathrm{~V}_{\mathrm{z}}, \mathrm{CL}$ for RDV in cohort 2. ${ }^{\mathrm{b}}$ Five for $A \mathrm{UC}_{\text {inf }}, \mathrm{t}_{1 / 2}$ for GS-441524. ${ }^{\mathrm{C}}$ Four for $\mathrm{AUC} \mathrm{C}_{\text {inf }}, \mathrm{t}_{1 / 2}$ for GS-704277 in cohort 1. Values presented to three significant figures. 
Table 3 Pharmacokinetic parameters of RDV, GS-441524, and GS-704277 in cohorts 7-9 of the single-ascending-dose study

\begin{tabular}{|c|c|c|c|}
\hline Parameter & $\begin{array}{c}\text { Cohort } 7 \\
75 \text { mg lyophilized formulation } \\
\text { 2-hour infusion } N=10\end{array}$ & $\begin{array}{c}\text { Cohort } 8 \\
150 \mathrm{mg} \text { lyophilized formulation } \\
\text { 2-hour infusion } N=10\end{array}$ & $\begin{array}{c}\text { Cohort } 9 \\
75 \text { mg lyophilized formulation } \\
30 \text {-minute infusion } N=9\end{array}$ \\
\hline \multicolumn{4}{|l|}{ RDV } \\
\hline $\mathrm{AUC}_{\mathrm{inf}}, \mathrm{h}^{\bullet} \mathrm{ng} / \mathrm{mL}$ & $1840(17.1)$ & 3260 (22.2) & 1250 (19.6) \\
\hline $\mathrm{AUC}_{\text {last}}, \mathrm{h}^{\bullet} \mathrm{ng} / \mathrm{mL}$ & $1830(17.1)$ & 3270 (21.3) & $1250(19.7)$ \\
\hline $\mathrm{C}_{\max }, \mathrm{ng} / \mathrm{mL}$ & $1720(28.4)$ & $2720(35.0)$ & 2930 (29.2) \\
\hline$T_{\max }$, hours & $2.00(1.97-2.05)$ & $1.99(1.97-2.03)$ & $0.50(0.50-0.50)$ \\
\hline$t_{1 / 2}$, hours & $0.84(0.80-0.96)$ & $1.11(0.97-1.80)$ & $1.00(0.85-1.03)$ \\
\hline \multicolumn{4}{|l|}{ GS-441524 } \\
\hline $\mathrm{AUC}_{\text {inf }}, \mathrm{h}^{\bullet} \mathrm{ng} / \mathrm{mL}$ & $2200(18.4)$ & $4330(22.2)$ & 2020 (30.9) \\
\hline $\mathrm{AUC}_{\text {last }}, \mathrm{h}^{\bullet} \mathrm{ng} / \mathrm{mL}$ & $2090(19.0)$ & 4190 (22.2) & $1920(32.8)$ \\
\hline $\mathrm{C}_{\max }, \mathrm{ng} / \mathrm{mL}$ & $77.5(21.0)$ & $148(26.5)$ & $69.1(32.8)$ \\
\hline$T_{\max }$, hours & $3.25(2.75-4.00)$ & $4.00(3.50-4.00)$ & $3.50(2.50-5.00)$ \\
\hline$t_{1 / 2}$, hours & $22.9(21.7-27.0)$ & $26.3(24.2-28.7)$ & 26.7 (25.0-26.9) \\
\hline \multicolumn{4}{|l|}{ GS-704277 } \\
\hline $\mathrm{AUC}_{\text {inf }}, \mathrm{h}^{\bullet} \mathrm{ng} / \mathrm{mL}$ & 295 (27.9) & $619(24.6)$ & $281(39.0)$ \\
\hline $\mathrm{AUC}_{\text {last}}, \mathrm{h}^{\bullet} \mathrm{ng} / \mathrm{mL}$ & $287(28.3)$ & $611(24.9)$ & $274(40.0)$ \\
\hline $\mathrm{C}_{\max }, \mathrm{ng} / \mathrm{mL}$ & $114(25.7)$ & $234(28.8)$ & $156(43.0)$ \\
\hline$T_{\max }$, hours & $2.02(1.97-2.25)$ & $1.99(1.97-2.25)$ & $0.50(0.50-1.00)$ \\
\hline$t_{1 / 2}$, hours & $1.52(1.43-1.76)$ & $1.75(1.36-1.85)$ & $1.30(1.23-1.44) \mid$ \\
\hline
\end{tabular}

Subjects received RDV lyophilized i.v. formulation administered over a 2-hour infusion in cohorts $7(75 \mathrm{mg})$ and $8(150 \mathrm{mg})$ and over a 30 -minute period in cohort $9(75 \mathrm{mg})$. All pharmacokinetic parameters are reported as mean (\% coefficient of variation), except for $\mathrm{T}_{\max }$ and $\mathrm{t}_{1 / 2}$, which are reported as median (Q1, Q3). One subject in cohort 9 did not receive the full volume of the intravenous dose; data for this subject were excluded. Values presented to three significant figures. AUC $_{\text {inf }}$, area under the curve vs. time curve extrapolated to infinity; $\mathrm{AUC}_{\text {lst, }}$, area under the curve from time zero to the last quantifiable concentration; $\mathrm{C}_{\max }$, peak plasma concentration; RDV, remdesivir; $\mathrm{t}_{1 / 2}$, terminal half-life; $\mathrm{T}_{\max }$, time to peak concentration.

Tables 2, 3. Pharmacokinetics of RDV, intermediate Ala metabolite (GS-704277), and GS-441524 in healthy volunteers adapted from Humeniuk et al. Clin. Transl. Sci. (2020) following administration of RDV at doses indicated in either solution form (top table) or as a reconstituted lyophilized powder (bottom table). For cohorts receiving at least $30 \mathrm{mg}$ of RDV, GS-441524 is the persistent species that sees the greatest systemic exposure.

For participants receiving $30 \mathrm{mg}, 75 \mathrm{mg}, 150 \mathrm{mg}$, or $225 \mathrm{mg}$ of RDV, the area-under-the-curve (AUC) for GS-441524 was consistently higher than that for RDV (AUClast) ${ }^{27}$. In Molar terms, the difference is even higher given that GS-441524 has a Mw half that of RDV, such that the molar AUC for GS441524 is at least 3-times that of intact RDV. This indicates that total drug exposure to GS-441524 was higher than that of RDV and suggests that GS-441524 may be the main driver of anti-SARS-CoV2 activity, especially in the pneumocytes (discussed in greater detail in Section 4.2.1). That GS441524 may be primarily responsible for anti-SARS-CoV-2 activity is further supported by a set of in vitro pulsed versus continuous RDV dosing experiments conducted by Wang and colleagues ${ }^{33}$. Short exposure to RDV (pulsed, $3 \mathrm{~h}$ ) resulted in no antiviral activity by RDV, even though cells were pre-treated with RDV for $1 \mathrm{~h}$ before being infected with SARS-CoV-2 (Figure 6, green bar). In sharp contrast, continuous exposure (48 h) to RDV resulted in approximately $30-60 \%$ viral inhibition (Figure 6, pink, navy bars). One limitation to these data is that RDV is a p-glycoprotein (p-gp) substrate and the Vero6 cell line expresses high levels p-gp, an efflux transporter ${ }^{34,35}$. It is unclear whether pneumocytes, the main site of SARS-CoV-2 replication ${ }^{36}$, also express high levels of p-gp. Still, Wang's data could indicate that short exposure to RDV (similar to what is observed in vivo) 
may be insufficient to generate an antiviral response in many cell types that normally express robust levels of p-gp.

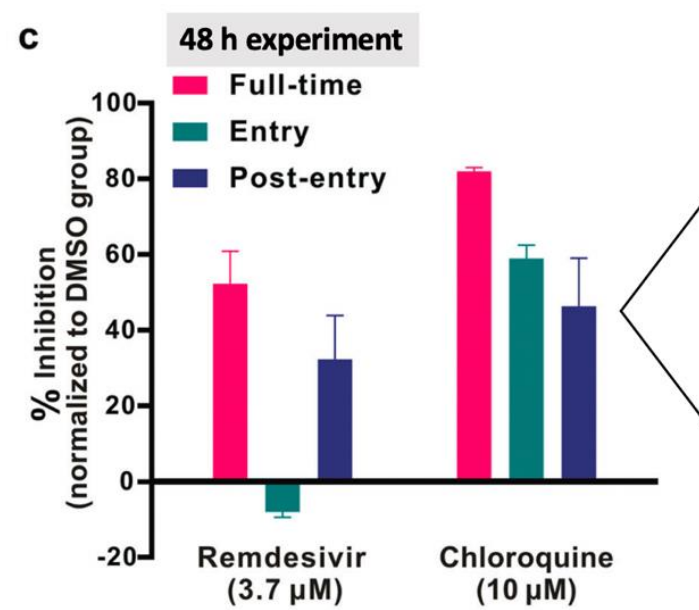

Fig. 1 The antiviral activities of the test drugs against 2019-nCoV in vitro. a Vero E6 cells were infected with 2019-nCoV at an MOI of 0.05 in the treatment of different doses of the indicated antivirals for $48 \mathrm{~h}$. The viral yield in the cell supernatant was then quantified by qRT-PCR. Cytotoxicity of these drugs to Vero E6 cells was measured by CCK- 8 assays. The left and right $Y$-axis of the graphs represent mean \% inhibition of virus yield and cytotoxicity of the drugs, respectively. The experiments were done in triplicates. $\mathbf{b}$ Immunofluorescence microscopy of virus infection upon treatment of remdesivir and chloroquine. Virus infection and drug treatment were performed as mentioned above. At $48 \mathrm{~h}$ p.i., the infected cells were fixed, and then probed with rabbit sera against the NP of a bat SARS-related CoV ${ }^{2}$ as the primary antibody and Alexa 488-labeled goat anti-rabbit IgG $(1: 500 ; \mathrm{Abcam})$ as the secondary antibody, respectively. The nuclei were stained with Hoechst dye. Bars, $100 \mu \mathrm{m}$. c and d Time-of-addition experiment of remdesivir and chloroquine. For "Full-time" treatment, Vero E6 cells were pre-treated with the drugs for $1 \mathrm{~h}$, and virus was then added to allow attachment for $2 \mathrm{~h}$. Afterwards, the virus-drug mixture was removed, and the cells were cultured with drug-containing medium until the end of the experiment. For "Entry" treatment the drugs were added to the cells for $1 \mathrm{~h} \mathrm{before}$ viral attach For "Post-entr" experiment cells were infected with $2019-\mathrm{nCoV}$ at an $\mathrm{MOI}$ of 0.05 , and virus yield in the infected cell supernatants was quantified by qRT-PCR c and NP expression in infected cells was analyzed by Western blot $\mathbf{d}$ at $14 \mathrm{~h}$ p.i.
ell

Figure 6. Short exposure to RDV in VeroE6 cells (green bar) does not yield anti-SARS-CoV-2 activity whereas long, continuous exposure to RDV does (pink, navy bars). Adapted from Figure 1 in Wang et al. Cell Res. $(2020)^{33}$.

The enzymes required to bioactivate McGuigan prodrugs, such as RDV, are expressed at highest levels in hepatocytes (liver cells, described in Section 4.3). Thus, like other McGuigan prodrugs, RDV experiences a high degree of first-pass metabolism and second-pass liver extraction. This translates to high levels of active NTP in hepatocytes, which is desirable for treating viral infections of hepatocytes such as hepatitis, but counterproductive for infections of other tissues, such as the lower respiratory tract in the case of SARS-CoV-2. In fact, RDV, was originally developed and investigated for the treatment of hepatitis ${ }^{7,37}$ and the FDA-approved drug Sofosbuvir is also a prodrug of the McGuigan class ${ }^{38}$ (Figure 7). In agreement, the EMA for RDV explicitly states "The Sponsor [Gilead] claims that remdesivir is not suitable for oral delivery as its poor hepatic stability would likely result in almost complete first-pass clearance" (page 27). 


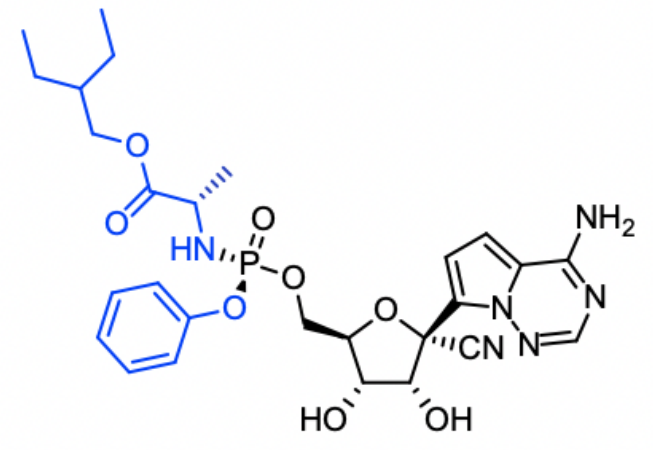

Remdesivir

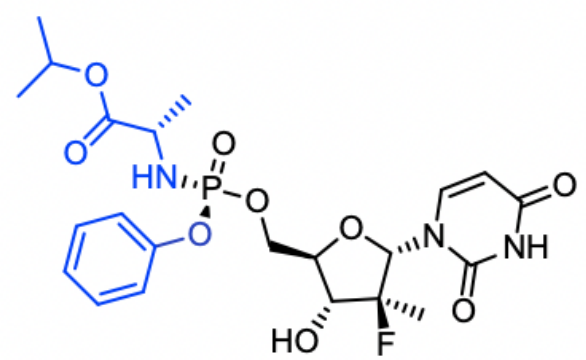

Sofosbuvir

Figure 7. RDV and Sofosbuvir are both phosphate prodrugs of the McGuigan class, making them subject to hepatic extraction. McGuigan prodrug moieties (phenol/L-Alanine ester) are indicated in blue.

Even with intravenous (IV) dosing, RDV is still subject to second-pass liver-extraction. The EMA notes that ${ }^{14} \mathrm{C}$-RDV distribution studies show "High levels of radioactivity were observed in kidney, kidney medulla, liver, and arterial wall9,29" (kidney reflects elimination of the Ala-metabolite). Poor hepatic stability of McGuigan prodrugs such as RDV has been explicitly noted by Gilead scientists in their $2017 \mathrm{~J}$. Med. Chem. publication17. The EMA further states that, "Secondary pharmacology studies indicate that human hepatocytes may be sensitive to remdesivir cytotoxicity at clinically relevant exposures." (page 26) ${ }^{29}$. In concurrence with these initial concerns, emerging case reports on the use of RDV in SARS-CoV-2 infected patients have cited increases in alanine aminotransferase (ALT) as sufficiently adverse events to cease treatment ${ }^{39}$. Given that the anti-Covid-19 effects of RDV have been moderate, at best ${ }^{13,14}$, it begs the question as to why dose-escalation is not possible: the most reasonable conclusion is that adverse events related to hepatotoxicity preclude dose escalation for stronger antiviral effects.

In sum, IV dosing of RDV results in predominant drug deposition in the liver and elimination by the kidneys ${ }^{40}$. The high liver deposition is associated with hepatoxicity and precludes oral administration or higher dosing.

\subsubsection{Remdesivir is poorly suited for delivery of active drug to cells critical in the pathogenesis of Covid-19}

Obligatory enzymatic removal of the phosphate prodrugs on RDV translates to cells or tissues with high expression of the required bioactivating enzymes (in particular, CES1/CTSA ${ }^{19,31}$ ) preferentially accumulating active NTP. By extension, cells or tissues with comparatively lower expression of CES1/CTSA would have lower accumulation of the active NTP due to the inability to metabolize RDV to the active NTP at the same rate as cells/tissues with high expression of CES1/CTSA. Interrogation of the Human Protein Atlas public domain proteomic/transcriptomic database for expression of 
CES1, CTSA and HINT1 reveals high expression in hepatocytes and myeloid lineage, but minimal expression in pneumocytes, the cell types most relevant for SARS-CoV-2 replication and Covid-19 pathology (Figure 8).

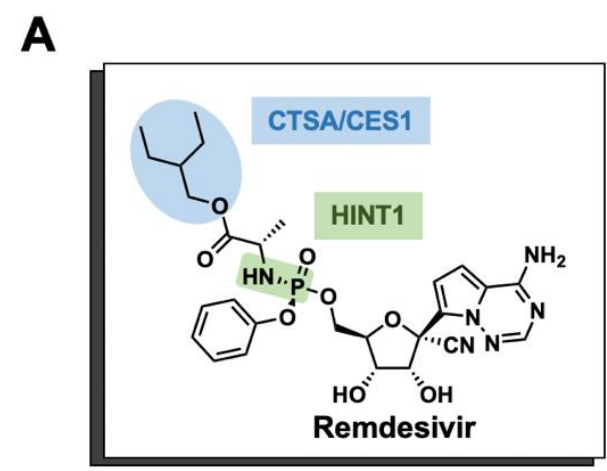

B
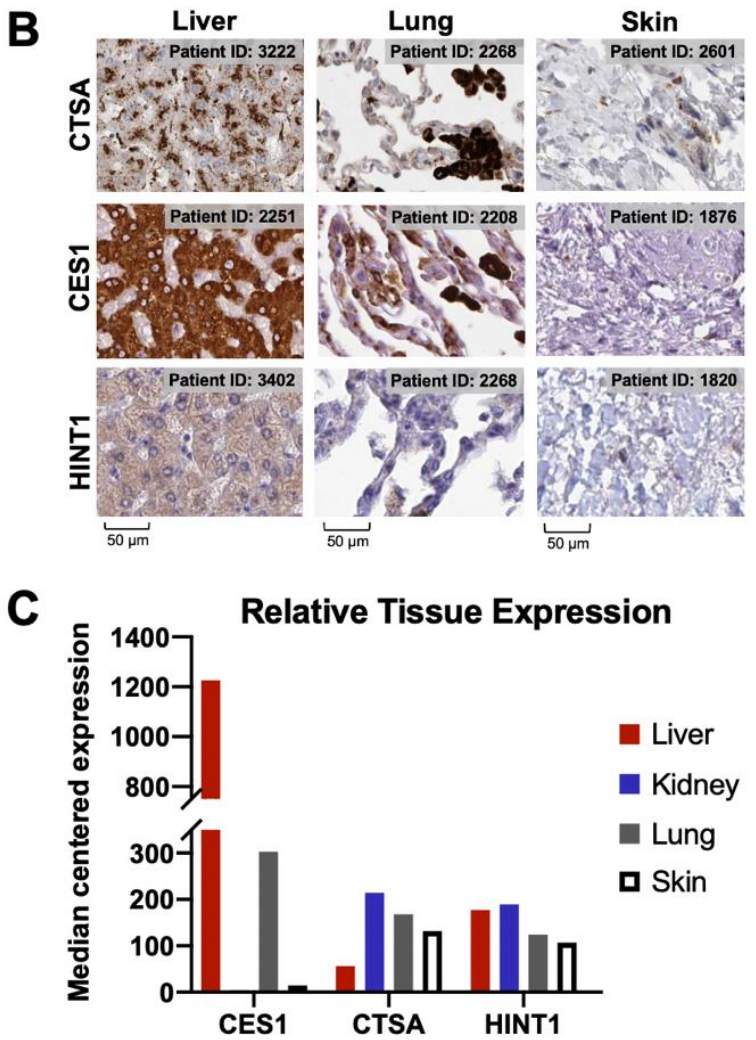

Figure 8. RDV bioactivating enzymes (specifically CES1 and CTSA) are highly expressed in the liver with minimal expression in the lungs. (A) Labile pro-drug moieties on remdesivir with corresponding bioactivation enzymes. (B) Immunohistochemistry images from the Human Protein Atlas indicating expression for ProTide bioactivating enzymes. Brown regions indicate enzyme expression while blue regions indicate absent expression. For the lung, pneumocytes-cells frequently infected by Covid-19-are characterized by a threadlike appearance. Expression in the liver is generally higher compared to lung for all enzymes. For CTSA, darkly stained regions are associated with macrophages in the lung. IHC images for the skin are included to show lack of enzyme expression. Antibodies used: CTSA (CAB024930), CES1 (HPA046717), HINT1 (HPA044577). (C) Normalized mRNA expression of initial prodrug bioactivating enzymes for RDV (CES1/CTSA/HINT1) adapted from the Human Protein Atlas reported as median-centered protein-coding transcripts per million (pTPM). Note that mRNA at the tissue level does not distinguish between cell types. The CES1 mRNA levels in the lung is driven by alveolar macrophages rather than pneumocytes (B).

While mRNA expression of CES1 is evident in lung, close inspection of the cellular components of the lung reveals that both CES1 and CTSA are highly expressed in lung macrophages, rather than in the type I/II alveolar cells (pneumocytes) which are the main site of SARS-CoV-2 replication ${ }^{36,41}$ (Figure 9). Low expression of CES1/CTSA in pneumocytes portends low levels of active NTP formation in the cell type most relevant to SARS-CoV-2 pathology. Gilead has recently announced 
plans to begin investigating an inhalable form of $\mathrm{RDV}^{42}$. These data also forecast issues that could arise from emerging trials with inhalable RDV: high expression of CES1/CTSA in lung macrophages will likely result in on-target toxicities to these human or mitochondrial RNA polymerases in cells. Conversely, low expression of CES1/CTSA in pneumocytes portends low levels of active NTP formation in the cell type most relevant to SARS-CoV-2 pathology.
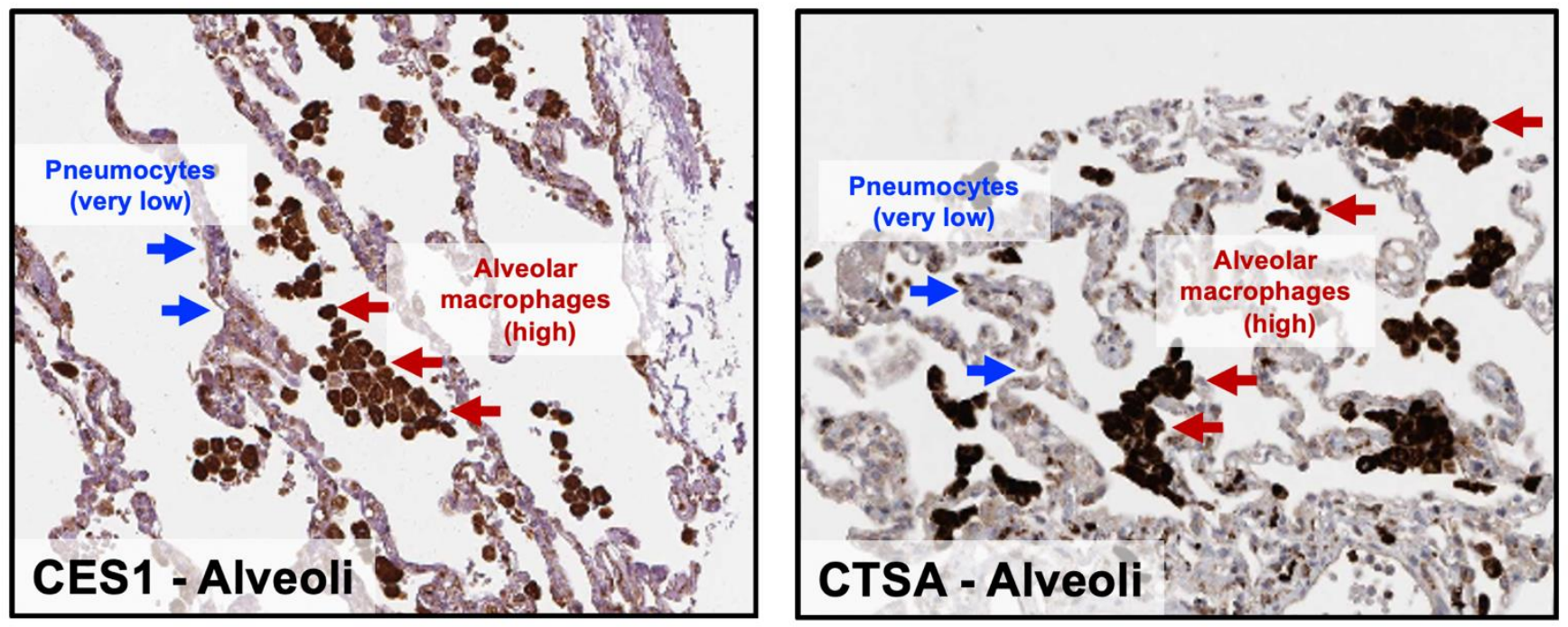

Figure 9. CES1/CTSA are highly expressed in alveolar macrophages rather than pneumocytes. Immunohistochemistry slides of the lung adapted stained for either CES1 (left) or CTSA (right) from the Human Protein Atlas. Brown staining indicates expression of the given enzyme. For both CES1 and CTSA, expression is concentrated in alveolar macrophages (spherical appearance), with minimal expression (purple/blue) in pneumocytes (thread-like appearance).

In addition to public domain database data showing preferential expression of CES1/CTSA in the liver and lung macrophages, independent validation by single-cell RNA-seq provided by Robert Lorenz Chua, Christian Conrad, and Roland Eils (Eils Laboratory) from the University of Berlin have corroborated these results in SARS-CoV-2-infected patients post-mortem (Figure 10, unpublished). 


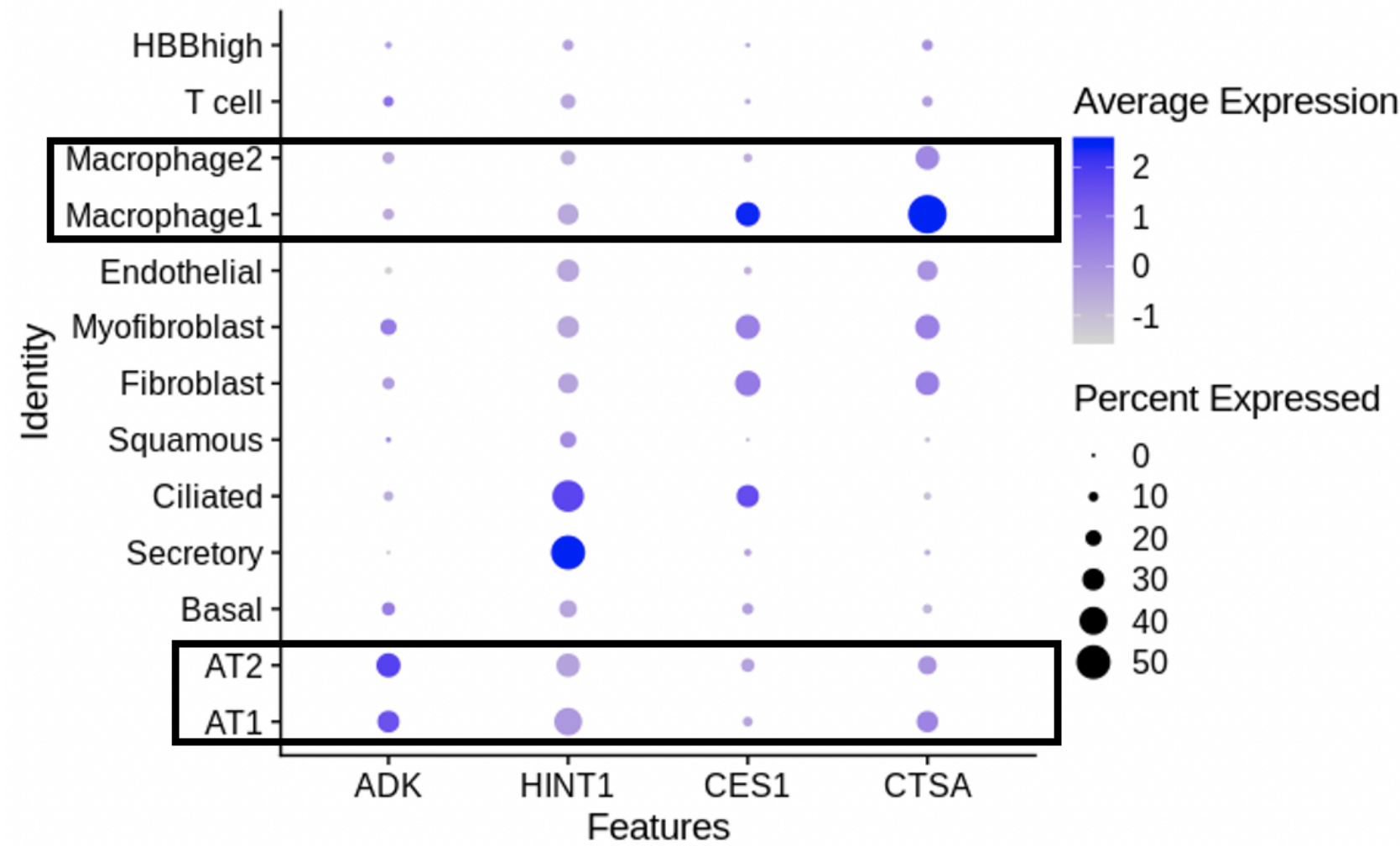

Figure 10. Unpublished single-cell RNA-seq expression data for ADK, HINT1, CES1, and CTSA in postmortem lung tissue of SARS-CoV-2-infected patients kindly shared by the Eils Laboratory (Chua, Conrad and Eils). ADK is the bioactivating enzyme for GS-441524; CES1/CTSA/HINT1 are the bioactivating enzymes for RDV. Circle size indicates the percentage of cells expressing the given enzyme while purple intensity indicates high or low expression. Macrophages exhibit high expression of CES1/CTSA. However, alveolar type I/II (AT1/AT2) cells show minimal expression of CES1/CTSA. In contrast, ADK (bioactivating enzyme for GS-441524) is highly expressed in both AT1/2 cells.

\subsection{Administration of remdesivir requires complex excipients associated with nephrotoxicity}

RDV has a molecular weight of $602.58 \mathrm{~g} / \mathrm{mol}$ and a predicted $\log \mathrm{P}$ value of 1.29 (logP, partition coefficient between water and an organic phase such as octanol; $\log \mathrm{P}>1$ indicates preferential partitioning into the organic phase). Due to its poor water solubility, complex excipients must be used to enable its dissolution in aqueous solvents. Currently, RDV is formulated in a $12 \%$ solution of sulfobutylether-ß-cyclodextrin (Captiso ${ }^{\circledR}$ ), a hydrophilic polymer that largely localizes to and is cleared by the kidneys ${ }^{43}$. Kidney-related adverse events related to the Captisol ${ }^{\circledR}$ excipient are thus likely. Another significant contributor to nephrotoxicity is accumulation of the intermediate Ala metabolite, which results from hydrolysis of the phenol prodrug moiety on the phosphate of RDV (Figure 3), which is also cleared by the kidneys (organic anion transporters, discussed in Section 
3.2, page 8$)^{29}$ due to its identity as an anionic molecule. Pre-clinical data summarized by the EMA document states, "Repeat-dose toxicity studies in rats (5,20,50 mg/kg for 14 days and 1, 3, $10 \mathrm{mg} / \mathrm{g}$ for 4 weeks) and studies in monkeys $(1,3,10 \mathrm{mg} / \mathrm{kg}$ for 14 days and 4 weeks) after intravenous injections identified the kidney as target organ (page 23) and "In the IV study of rhesus monkeys of Indian origin (TX-399-2021), remdesivir was administered at $0,5,10$, and $20 \mathrm{mg} / \mathrm{kg} /$ day for 7 days. Remdesivir-related morbidity, with subsequent early euthanasia, was noted in a single 20 $\mathrm{mg} / \mathrm{kg} /$ day animal. The cause of moribundity was attributed to remdesivir-related kidney findings" (page 24). Again, these data on kidney-related toxicities have been corroborated by emerging case study reports on RDV in SARS-CoV-2-infected patients ${ }^{39}$ and have also been verified in email correspondences with Dr. John Beigel, the lead author of the NIAID-sponsored controlled trial with $\mathrm{RDV}^{13}$. In the latter case, kidney toxicity related to the Captisol ${ }^{\circledR}$ excipient likely explains the Grade $3 / 4$ adverse events related to nephrotoxicity in both the RDV- (7.4\%) and placebo-treated $(7.3 \%)$ patients (pages 8-9 in Beigel et al. NEJM (2020)) ${ }^{13}$. Compared to RDV, GS-441524 has a lower molecular weight $(291.27 \mathrm{~g} / \mathrm{mol})$ and is more hydrophilic, which enables the use of alternate excipients that would avoid nephrotoxicity.

\section{Advantages of GS-441524 for Covid-19 treatment}

\section{Key points:}

- Predominant, persistent metabolite in circulation following administration of RDV $^{9,11,16,26,32}$

- Significantly easier to synthesize ${ }^{7,17}$

- Bioactivated by enzymes that are highly expressed in SARS-CoV-2-infected pneumocytes

- Excellent safety profile against primary human liver and kidney cells in vitro ${ }^{9}$ suggests feasibility of higher dosing and oral administration without hepatotoxicity

- Superior potency compared to RDV in SARS-CoV-2-infected cells in vitro in a cell line with similar RDV-bioactivating enzyme profile as pneumocytes ${ }^{10}$

- Exceptional efficacy against feline infectious peritonitis (96\% cure rate), which is caused by a feline coronavirus ${ }^{47,48}$, for which no vaccine had proved effective and which was previously uniformly fatal.

- Ability to treat neurological manifestations of corona virus, as evidenced by effectiveness against neurological feline infectious peritonitis ( $75 \%$ cure rate $)^{50}$

As briefly described in Section 3.2, RDV has a short half-life in human the blood, with GS-441524 being the predominant, persistent metabolite in circulation (Figures 4, 5; Tables 2, 3). GS-441524 has a half-life of approximately 24 hours in human blood 26,29 . This observation has been wellcorroborated by multiple studies across species (Table $\mathbf{1}$ ) and is epitomized by the approximately 
1,000-fold higher levels of GS-441524 compared to RDV following intravenous injection of RDV in non-human primates throughout a 7-day study (Figure 4) ${ }^{11}$.

\subsection{Simple synthesis, advantageous physiochemical properties, and implications thereof}

In contrast to RDV, which contains an arduous synthesis that has resulted in supply shortages and distribution issues, the comparative simplicity associated with the synthesis of GS-441524 would overcome these aforementioned issues with RDV. GS-441524 is an intermediate product in the synthesis of RDV. Of the 7 steps reported in the synthesis of RDV, GS-441524 is obtained after step $3^{17}$ (Figure 11, red box). Where RDV contains 6 chiral centers, GS- 441524 contains just 3. Fewer stereocenters on GS-441524 coupled with the absence of phosphate chemistry makes GS-441524 a significantly easier molecule to produce. From a metabolic standpoint, it is counterproductive undertake the additional 4 complicated steps to generate RDV when its phosphate prodrug is prematurely hydrolyzed to GS-441524 after administration.

Scheme 2. Second Generation Synthesis of $4 b^{a}$
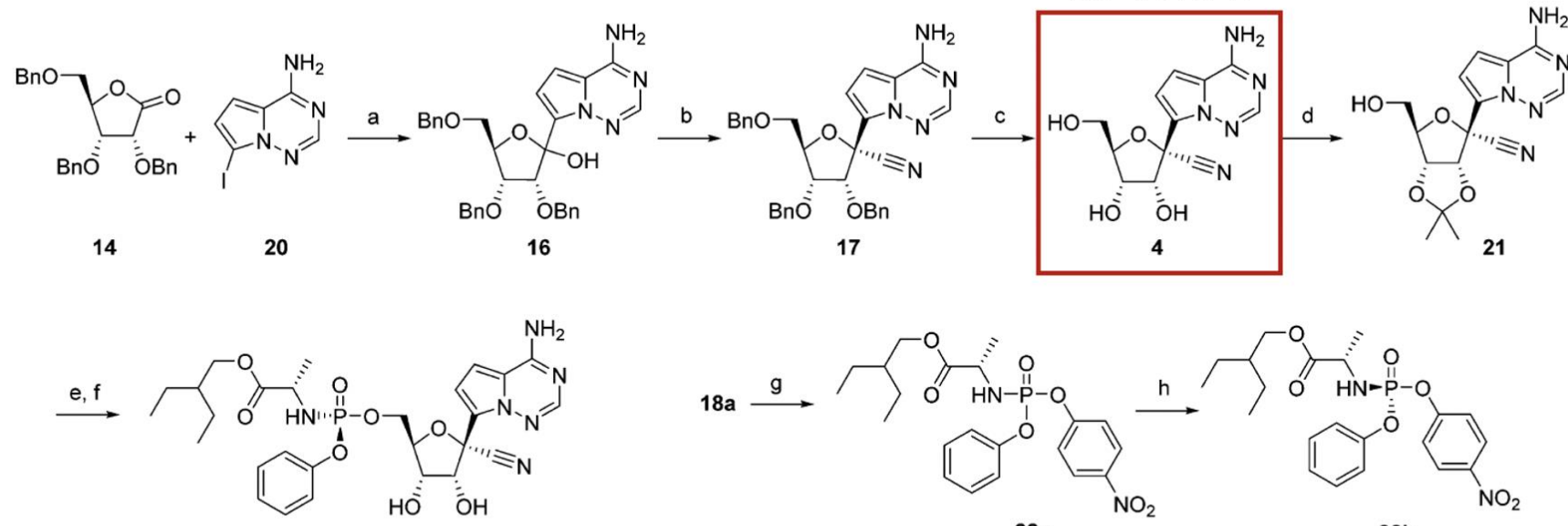

$4 \mathrm{~b}$

${ }^{a}$ Reagents and conditions: (a) TMSCl, $\mathrm{PhMgCl}, i$-PrMgCl-LiCl, THF, $-20^{\circ} \mathrm{C}, 40 \%$; (b) TMSCN, TfOH, TMSOTf, $\mathrm{CH}_{2} \mathrm{Cl}_{2}-78{ }^{\circ} \mathrm{C}, 85 \%$; $(\mathrm{c})$ $\mathrm{BCl}_{3}, \mathrm{CH}_{2} \mathrm{Cl}_{2},-20^{\circ} \mathrm{C}, 86 \%$; (d) 2,2-dimethoxypropane, $\mathrm{H}_{2} \mathrm{SO}_{4}$, acetone, rt, $90 \%$; (e) $22 \mathrm{~b}, \mathrm{MgCl}_{2},(\mathrm{i}-\mathrm{Pr}){ }_{2} \mathrm{NEt}, \mathrm{MeCN}, 50{ }^{\circ} \mathrm{C}, 70 \%$; (f) $37 \% \mathrm{HCl}$, THF, rt, 69\%; (g) OP(OPh) $\mathrm{Cl}_{2}, \mathrm{Et}_{3} \mathrm{~N}, \mathrm{CH}_{2} \mathrm{Cl}_{2}$, $-78{ }^{\circ} \mathrm{C}$, then 4-nitrophenol, $\mathrm{Et}_{3} \mathrm{~N}, 0{ }^{\circ} \mathrm{C}, 80 \%$; (h) $i-\mathrm{Pr}_{2} \mathrm{O}, 39 \%$.

Figure 11. Synthetic scheme of GS-441524 (4) en route to remdesivir (4b) from Scheme 2 in Siegel et al. J. Med. Chem. (2017) ${ }^{17}$. As shown in the scheme, GS-441524 can be obtained in 3 steps. 


\subsection{In vitro data demonstrating similar or superior potency in SARS-CoV-2 infected cells}

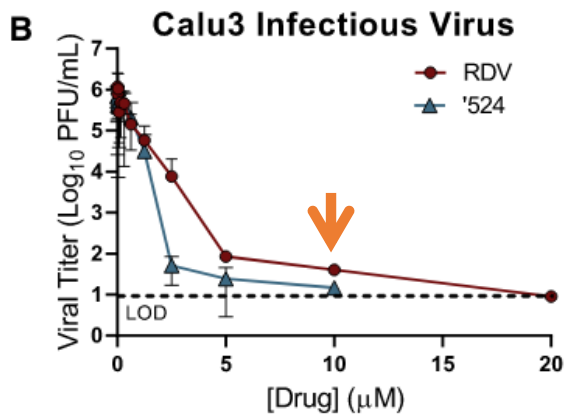

D
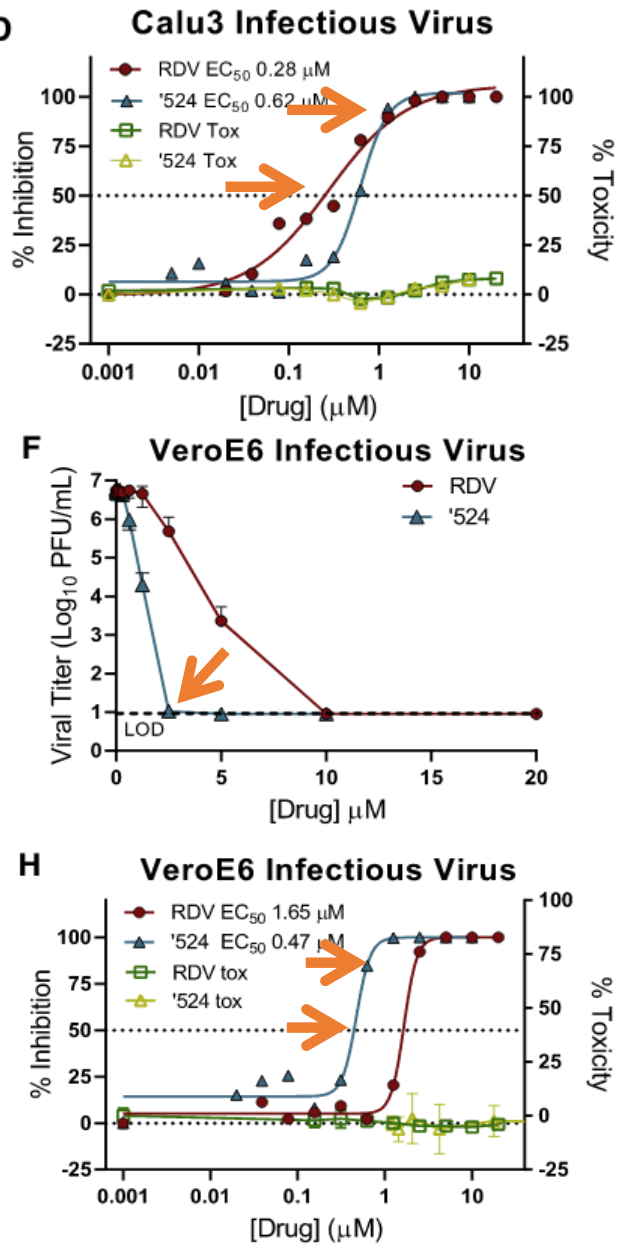

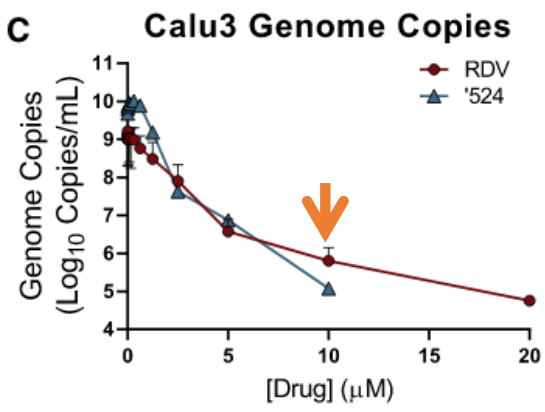

E

Calu3 Genome Copies

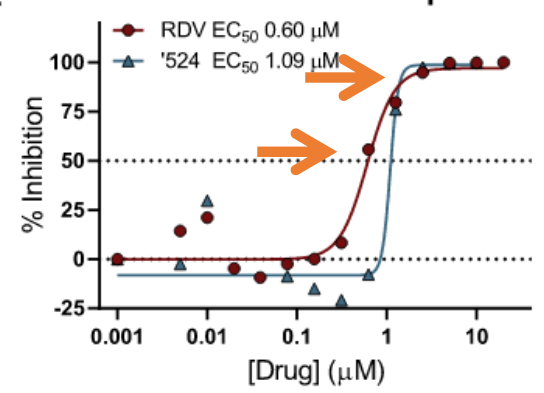

G VeroE6 Genome Copies

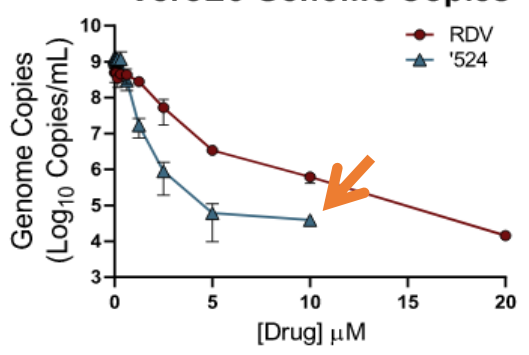

I VeroE6 Genome Copies

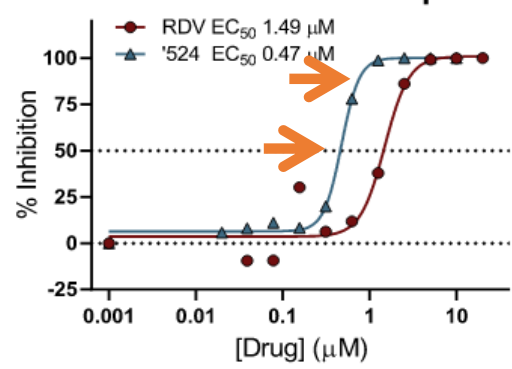

Figure 12. GS-441524 exhibits similar or superior anti-SARS-CoV-2 potency in vitro, as reported in Figure 2 from Pruijssers et al. Cell Rep. (2020). GS-441524 ('524) is indicated in blue. RDV is indicated in red.

A recent report by Pruijssers and colleagues ${ }^{10}$ has shown that GS-441524 ('524) is capable of: 1.) generating active NTP in human cells at levels similar or superior to RDV and 2.) exerting anti-SARSCoV-2 activity in vitro at clinically relevant doses (Figure 12). In both Calu3 and VeroE6 cells, GS- 
441524 reduces viral titers below detectable levels at lower concentrations compared to RDV (Figure 12, panels B, F. Calu3: $10 \mu \mathrm{M}$ for GS-441524 vs. $20 \mu \mathrm{M}$ for RDV; VeroE6: $\sim 2.5 \mu \mathrm{M}$ for GS441524 vs. $10 \mu \mathrm{M}$ for RDV). This pattern of antiviral activity between GS-441524 and RDV was also observed when the number of viral genome copies was measured (Figure 12, panels C, G). When $\mathrm{EC}_{50}$ values were compared between the two drugs in SARS-CoV-2-infected VeroE6 cells (Figure 12, panels H, I), GS-441524 showed significantly lower EC 50 (GS-441524: $0.47 \mu \mathrm{M}$ vs. RDV: $\sim 1.5$ $\mu \mathrm{M})$. $\mathrm{EC}_{90}$ values were also considerably lower for GS-441524 $(\sim 0.8 \mu \mathrm{M})$ compared to RDV $(\sim 2 \mu \mathrm{M})$. For Calu3 (Figure 12, panels D, E), GS-441524 exhibited a slightly higher $\mathrm{EC}_{50}$ value $(0.62-1.09 \mu \mathrm{M}$ compared to RDV (0.28-0.60 $\mu \mathrm{M})$; it should be noted that these differences in $\mathrm{EC}_{50}$ values are still the same order of magnitude. The EC90 values, which are arguably the more important value for antiviral activity, are essentially the same, with both drugs exhibiting an EC90 of $\sim 0.8-1 \mu \mathrm{M}$.

While both RDV and GS-441524 exhibit antiviral activity at levels that are not considered toxic to uninfected cells, only GS-441524 is continuously sustained at concentrations required to achieve $\mathrm{EC}_{50}$ values in SARS-CoV-2 infected cells in vitro (Figure 13).
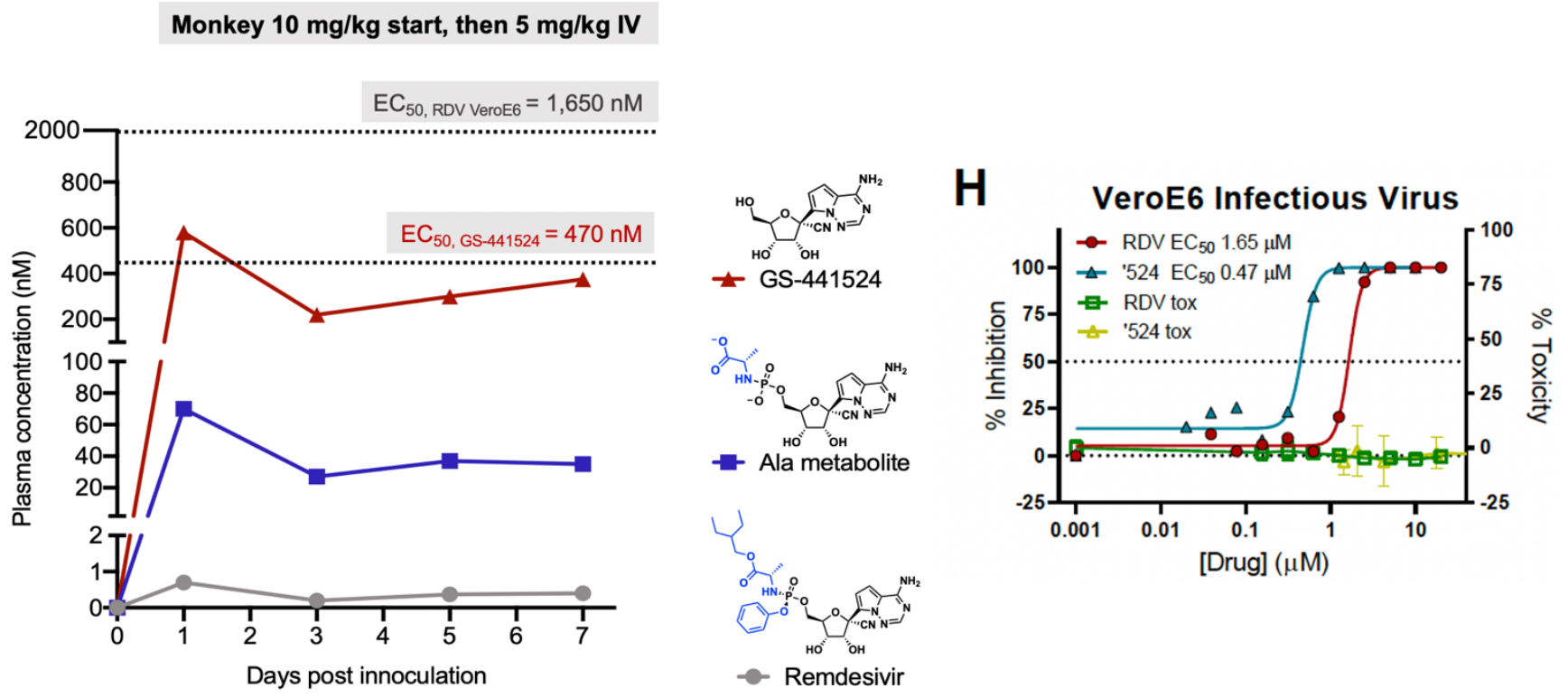

Figure 13. Concentrations of GS-441524 is sustained in plasma are sufficient to achieve the anti-SARS-CoV2 EC50 value in vitro. Left: Plasma levels of RDV metabolites following intravenous injection in rhesus macaques over a 7-day treatment course, adapted from Extended Data Figure S1 in Williamson et al. Nature (2020). GS-441524 is indicated in red. RDV is indicated in grey. Right: Panel H from Figure 2 in Pruijssers et al. Cell Rep. (2020). 


\subsection{GS-441524 is not hepatotoxic and is well-suited for pneumocyte-targeted delivery}

Some may note that the cell type in which GS-441524 demonstrated clear superiority over RDV in SARS-CoV-2 infected cells (VeroE6) is a kidney cell line derived from monkeys and is thus a poor representation of the SARS-CoV-2 infected pneumocytes. However, this assumption is incorrect. In fact, the pattern of bioactivating enzyme expression in VeroE6 cells closely reflects that observed in SARS-CoV-2-infecetd pneumocytes thus makes it well-suited to studying the antiviral activity of GS441524. As described in Section 3.3, the AT1/2 cells are the main site for SARS-CoV-2 infection. While formal biochemical studies on the initial phosphorylation of GS-441524 to the monophosphate have yet to be conducted, the first enzyme involved in this reaction is likely adenosine kinase (ADK) due to the structural similarity between GS-441524 and adenosine. Some have suggested that the initial phosphorylation reaction of GS-441524 occurs inefficiently, pointing to the rate-limiting phosphorylation of the sofosbuvir nucleoside (PSI-6206) by the enzyme deoxycytidine kinase $(\mathrm{dCK})^{9}$. However, a recent study by Friman and colleagues ${ }^{44}$ have demonstrated that, at least in the HepG2 cell line, GS-441524 is not a substrate of dCK (Figure 14). These data further suggest that ADK is likely the main phosphorylating enzyme for GS-441524.

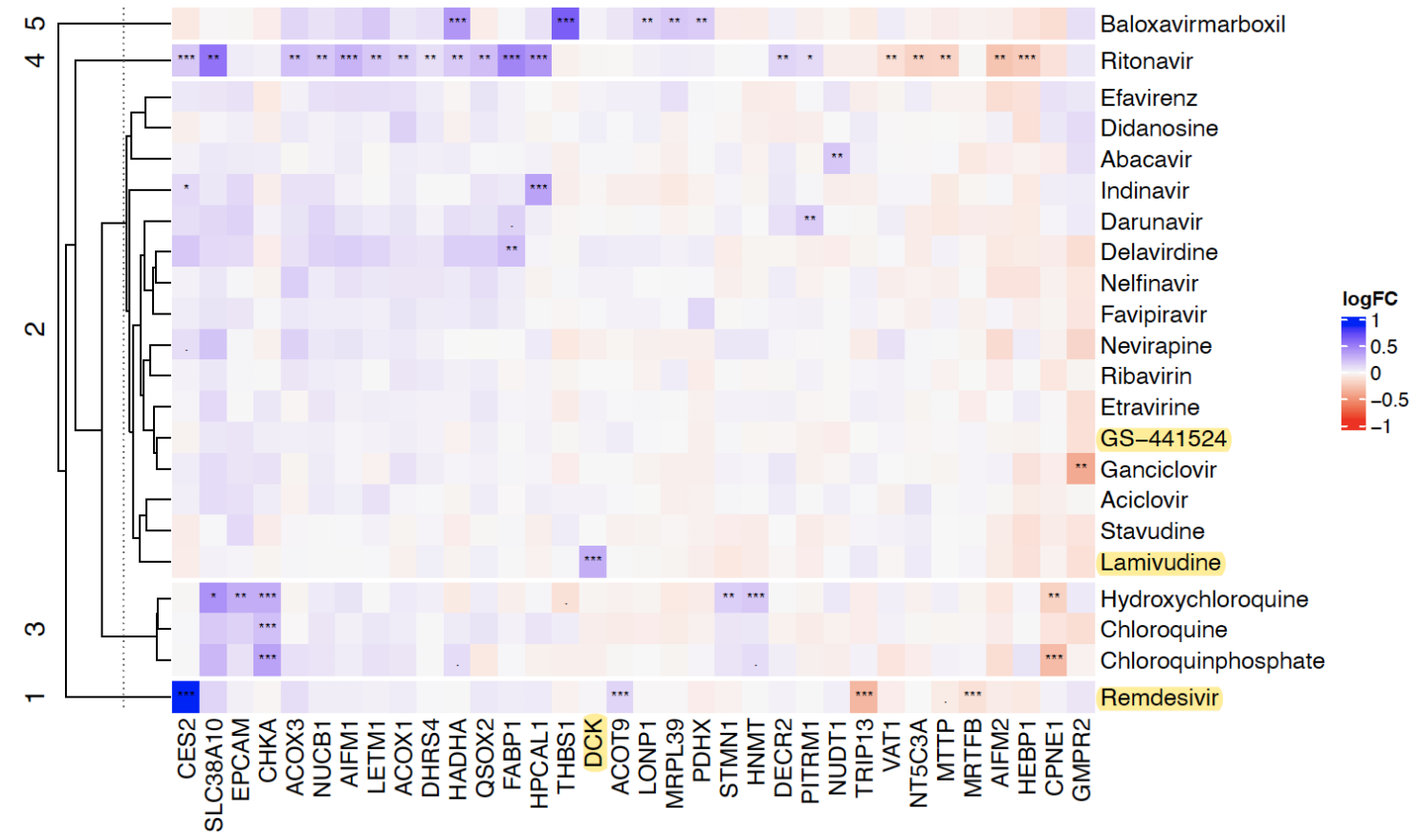

Figure 2. Heatmap of compound induced protein thermal stability changes in HepG2 cells treated with different antiviral compounds. Proteins found to be significantly changed ( $p \leq 0.01$ ) in at least one compound included into the plot.

Figure 14. dCK is unlikely to be the main enzyme responsible for initial phosphorylation of GS-441524, as indicated by extremely low intensity of blue for change in DCK thermal stability. Lamivudine, a cytidine analogue, serves as a "positive control" for DCK, as indicated by the mild intensity of blue associated with DCK thermal stability. 
Single-cell RNA-seq data obtained from post-mortem lung tissue of SARS-CoV-2-infected patients has been provided by Robert Lorenz Chua, Christian Conrad, and Roland Eils (Eils Laboratory) from the University of Berlin and unambiguously show that ADK is highly expressed in AT1/2 cells (Figures 10, 15) while RDV bioactivating enzymes (CES1/CTSA) are minimally expressed in AT1/2 cells. In their discussion of the data, Pruijssers and colleagues state the following as an explanation for the lower potency of RDV in VeroE6 cells (page 6):

"In contrast, RDV was 2-fold less potent than GS-441524 in Vero E6 cells. The relative potency of the two compounds was directly linked to intracellular concentration of the active TP metabolite, suggesting an altered uptake and/or intracellular metabolism of RDV, consistent with a previous report describing inefficient metabolism of the nucleotide prodrug sofosbuvir in Vero cells (Mumtaz et al., 2017)."”10

The data presented by Pruijssers and colleagues (Figure 12) is thus a highly encouraging projection for the ability of GS-441524 to exert anti-SARS-CoV-2 activity in patients.
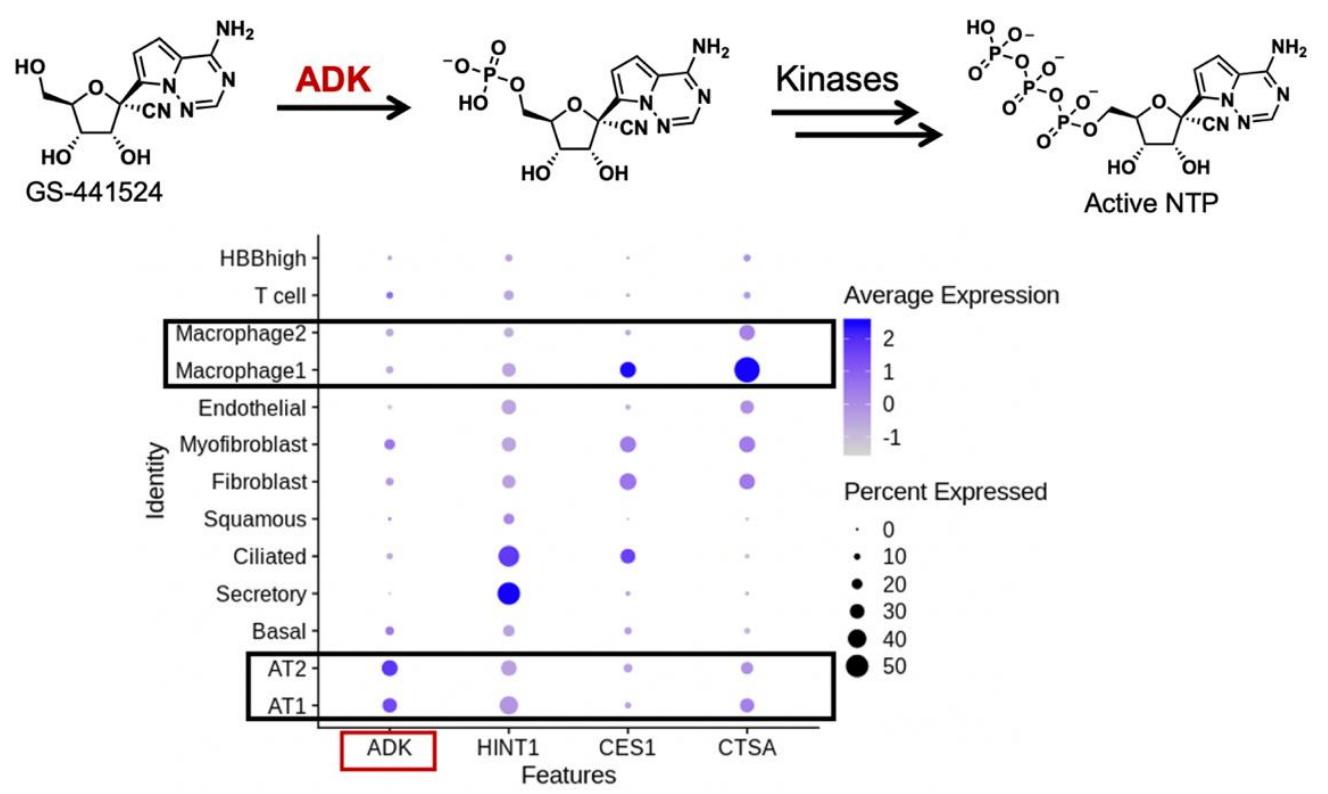

Figure 15. Bioactivation mechanism for GS441524 and expression of ADK (red box) in postmortem lung tissue from SARS-CoV-2 infected patients. ADK is highly expressed in AT1/2 cells. Unpublished single-cell RNA-seq data kindly shared by the labs of Eils, Chua and Conrad.

In addition to being well-suited for delivery of the active NTP in AT1/2 cells, GS-441524 has demonstrated an excellent safety profile against other tissues such as the liver and kidney in vitro. Comparison of the toxicity data between GS-441524 and RDV in primary human hepatocytes and renal proximal tubular epithelial cells evidence $\mathrm{CC}_{50}$ values of $>100 \mu \mathrm{M}$ for GS-441524 versus 2.5-18 $\mu \mathrm{M}$ for RDV, indicating a greater safety profile for GS-441524 (Figure 16). Unlike RDV, these in vitro data support the absence of hepatotoxicity with GS-441524, consistent with its mechanism of bioactivation (see Section 5.3). These in vitro data in cells relevant in first-pass metabolism strongly suggest that GS-

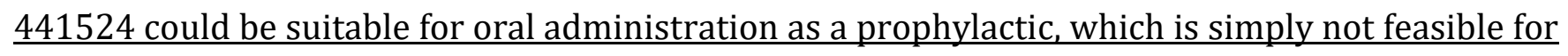
RDV. 
Extended Data Table 1 | In vitro cytotoxicity of GS-5734 and Nuc in human cell lines and primary cells

\begin{tabular}{llll}
\hline & \multicolumn{2}{c}{$\mathrm{CC}_{50}(\mu \mathrm{M})^{*}$} \\
\cline { 2 - 4 } & GS-5734 & Nuc & Puromycin \\
\hline Human cell lines & & $>100$ & $0.53 \pm 0.10$ \\
HEp-2 & $6.0 \pm 1.5$ & $>100$ & $0.73 \pm 0.01$ \\
HepG2 & $3.7 \pm 0.2$ & $>100$ & $0.52 \pm 0.11$ \\
PC-3 & $8.9 \pm 1.6$ & $69.3 \pm 25.7$ & $0.12 \pm 0.03$ \\
MT-4 & $1.7 \pm 0.4$ & $>100$ & $1.5 \pm 0.6$ \\
Human primary cells & & $>100$ & $1.1 \pm 0.3$ \\
Hepatocytes & $2.5 \pm 0.6$ & $>100$ & $6.8 \pm 1.4$ \\
Renal proximal tubular epithelial cells (RPTEC) & $12.9 \pm 6.2$ & $>100$ & $1.6 \pm 0.2$ \\
Quiescent PBMCs & $>20$ & $14.8 \pm 5.8$ &
\end{tabular}

*Drug concentrations reducing the cell viability by $50 \%\left(\mathrm{CC}_{50}\right)$ are presented. $\mathrm{All} \mathrm{CC}_{50}$ values represent the mean \pm s.d. of at least two independent experiments. Puromycin was included in experiments as a positive control for cytotoxicity.

Figure 16. GS-441524 exhibits an excellent safety profile against primary human hepatocytes and kidney cells in vitro. $\mathrm{CC}_{50}$ values are significantly greater for GS-441524 compared to RDV (GS-5734), as reported in Warren et al. Nature (2016) ${ }^{9}$; co-authored by Gilead scientists.

\subsection{In vivo data demonstrating exceptional safety and veterinary clinical efficacy against a related coronavirus}

The antiviral efficacy of GS-441524 has been extensively studied in the veterinary setting for cats infected with feline infectious peritonitis (FIP), which is caused by a closely related feline coronavirus (FCoV). FIP has long been considered a uniformly fatal disease ${ }^{45}$; vaccine development against $\mathrm{FCoV}$ has thus far been unsuccessful ${ }^{46}$. While seemingly bleak, a set of field studies conducted by Pedersen and colleagues have shown that GS-441524 is capable of curing cats afflicted with FIP at a 96\% cure rate when administered subcutaneously at $4 \mathrm{mg} / \mathrm{kg}^{47,48}$. No adverse events were observed. Similar to emerging data showing that SARS-CoV-2 has neurological manifestations 6,49 , FIP can also migrate to the brain. Pedersen's group demonstrated that neurological FIP could be resolved at a 75\% cure rate when GS-441524 was administered at 8-10 $\mathrm{mg} / \mathrm{kg}^{50}$. Again, no drug-related adverse events were noted. These data evidence the excellent safety profile of GS-441524, as evidenced by the feasibility of dose escalation, and also demonstrate the ability for GS-441524 to cross the blood-brain-barrier (BBB). As data on the whole-body afflictions associated with SARS-CoV-2 infection are emerging6, the latter point is particularly salient given the inability for RDV to cross the (BBB) due to its high molecular weight and because it is a substrate for p-glycoprotein efflux pumps ${ }^{29}$. All in vivo studies with GS-441524 against experimentally induced or naturally occurring FIP were conducted therapeutically, in which treatment was initiated at least 1-day post infection. In the case of experimental inoculation with FCoV in vivo, treatment with GS-441524 SC q24h began 3 days after clinical evidence of FIP (12-19 
days post infection ${ }^{48}$. This sharply contrasts pre-clinical in vivo studies that have been conducted with RDV, in which therapeutic treatment of animals (mice, non-human primates) began immediately ( $24 \mathrm{~h}$ ) after viral inoculation ${ }^{11,15,51}$ and demonstrates the ability for GS-441524 to exert robust antiviral activity even after delayed initiation of treatment, which more accurately reflects the clinical situation for patients who receive treatment for Covid-1914.

Because GS-441524 has not received regulatory approval 52 , a number of black market vendors have sold what appears to be GS-441524 in pill form, which has apparently shown efficacy against FIP53,54. This suggests a sufficient amount of GS-441524 is orally available to exert antiviral activity against FCoV.

\subsection{Potential to be administered as a prophylactic}

Because GS-441524 is not subject to hepatic extraction as RDV is, it could potentially be administered as an oral prophylactic agent for Covid-19. Prophylactic administration of GS-441524 is particularly attractive due to its long plasma half-life in humans $(\sim 24 \mathrm{~h})^{26,29}$; repeated dosing would result in bioaccumulation of GS-441524 and the active NTP. No data on the oral bioavailability of GS-441524 are published in the literature, however, Gilead has quoted a value of $5 \%$ in primates in email correspondences with their leadership. While this 5\% oral bioavailability may seem low, there are two critical factors that offset what would appear to be a low value. First, the extremely long half-life of GS-441524 in human plasma ${ }^{26,29}$ enables the possibility for multi-day dosing and bioaccumulation of the drug. Second, the poor correlation between oral bioavailability in non-human primates and that in humans has been well-documented in the literature, suggesting that the oral bioavailability of GS-441524 in humans may likely be higher than the claimed 5\% value ${ }^{55}$. For example, administration of the successful hepatitis nucleotide analogue, Sofosbuvir (developed by Gilead), in monkeys results in active triphosphate levels approximately 3-fold lower in than that in humans ${ }^{56}$. Thus, the extended half-life of GS-441524 in humans coupled with species differences in oral bioavailability suggest that it may be viable to administer GS-441524 orally.

One of the best-known examples highlighting the efficacy of prophylactic antiviral treatment is the pre-exposure prophylaxis regiment for HIV/AIDS 57 , in which a combination of either tenofovir disoproxil fumarate (TDF)/emtricabine (FTC) or TDF/lamivudine is used. A study investigating the efficacy of combined TDF/FTC prophylactic treatment compared to placebo found a $44 \%$ reduction in the probability of HIV-1 acquisition in men who have sex with men or transgender women ${ }^{58}$. Another study comparing the effects of placebo, TDF, and combined TDF/FTC showed that both oral administration of TDF or combined TDF/FTC treatment were effective at protecting against HIV-1 transmission amongst heterosexual men and women ${ }^{59}$. With TDF alone, there was a $67 \%$ reduction in HIV-1 incidence. Combination treatment with TDF/FTC resulted in a 75\% reduction in HIV-1 incidence ${ }^{59}$. Both studies demonstrate the ability for combined TDF/FTC treatment to significantly reduce rates of HIV transmission. The results showing comparable prophylactic efficacy between 
combined TDF/FTC and TDF alone amongst heterosexual men and women epitomize the idea that prophylactic treatment does not have to be equipotent to therapeutic treatment. That single agent prophylactic use of TDF can yield a $67 \%$ reduction in HIV transmission ${ }^{59}$ starkly contrasts the inability for TDF to be used as a monotherapy for post-infection treatment. Therapeutic treatment of HIV/AIDS typically requires a combination of three different classes of drugs (antiviral therapy) for sustained efficacy.

These data strongly suggest that a much lower degree of anti-viral efficacy is required for a drug in the prophylactic, compared to the post-infection setting. Given its good pre-clinical safety profile, GS-441524 stands to be an excellent candidate for a COVID-19 prophylactic. Such a prophylactic would be of critical importance to individuals at high risk of exposure, such as health care workers, first responders, and other essential workers operating in areas of high transmission risk.

\section{Summary}

GS-441524 is the parent nucleoside of RDV and predominant, persistent metabolite in circulation when RDV is administered $9,11,16,26,32$. Structurally, GS-441524 is significantly simpler to synthesize compared to RDV ${ }^{17}$; its simplicity would circumvent the challenges associated with large-scale RDV production and distribution.

Many of the dosing and safety limitations with RDV relate directly to its complex phosphate prodrug. Hepatotoxicity ${ }^{29}$ can be attributed to preferential bioactivation of the McGuigan prodrug moieties on RDV during hepatic extraction, due to high expression of CES1 and CTSA in the liver. Nephrotoxicity can be attributed both to the Captisol ${ }^{\circledR}$ excipient required to facilitate aqueous solubility of RDV in patients $13,29,39$ and to rapid serum hydrolysis of RDV to the intermediate Ala metabolite $9,11,16,26,32$, which is renal cleared ${ }^{29}$. Such issues would be circumvented by GS-441524, as it is bioactivated by ADK (highly expressed in SARS-CoV-2-infected pneumocytes) and has demonstrated excellent in vitro and in vivo safety data ${ }^{9}, 10$. The observation that the intermediate Ala metabolite is renal cleared coupled with the excellent safety profile of GS-441524 against primary human hepatocytes and kidney cells ${ }^{9}$ suggests that GS- 441524 could be dosed higher than the concentrations yielded by RDV and could be amenable to oral administration.

GS-441524 has demonstrated similar or superior anti-SARS-CoV-2 to RDV in SARS-CoV-2-infected cells in vitro at concentrations safely sustained in plasma (intravenous dosing of RDV yields concentrations of GS-441524 at 200-500 nM ${ }^{11} ; \mathrm{t}_{1 / 2}=24 \mathrm{~h}^{26,29}$ ). The ability for GS-441524 to treat neurological manifestations of FIP50 indicate its ability to cross the BBB, which is especially significant given the growing body of data demonstrating the whole-body afflictions of Covid-196. Its favorable chemical properties (low molecular weight, greater hydrophilicity, greater localization 
to AT1/2 cells) make it a promising candidate for outpatient administration (aerosolized formulations in simple excipients such as DMSO/saline or surfactant as well as oral, or subcutaneous administration) as either a therapeutic or prophylactic agent. Together, these data strongly support the safety and efficacy of GS-441524 and compel its clinical investigation for the treatment and prophylaxis of Covid-19.

\section{Frequently asked questions (FAQ)}

\section{Q1: If remdesivir degrades to GS-441524 in blood anyway, why would GS-441524 direct administration be either safer or more effective?}

A1: The vast majority of the administered dose of RDV is extracted by the liver or eliminated by the kidney in the form of the Ala-metabolite; only a minor fraction ${ }^{26}(<20 \%)$ remains in plasma for conversion to GS-441524. Direct administration of GS-441524 at the same dose as RDV yields much higher blood levels of GS-441524 because it is not subject to rapid liver extraction or kidney clearance. Unlike RDV, GS-441524 is not prone to liver bioaccumulation or hepatotoxicity (See Section 5.3). Thus, oral dosing or administering GS- 44124 at higher concentrations could be accomplished.

Q2: If the efficacy of remdesivir has only been modest so far, then why can't you just increase the dose?

A2: RDV has already been associated with signs of nephrotoxicity and hepatotoxicity at the current dose at which it is administered. Higher dosing would exacerbate these issues, making dose escalation unfeasible.

Q3: How do we know that GS-441524 present in blood is due to premature hydrolysis, rather than passive diffusion of GS-441524 out of the cell once RDV has been intracellularly metabolized? 


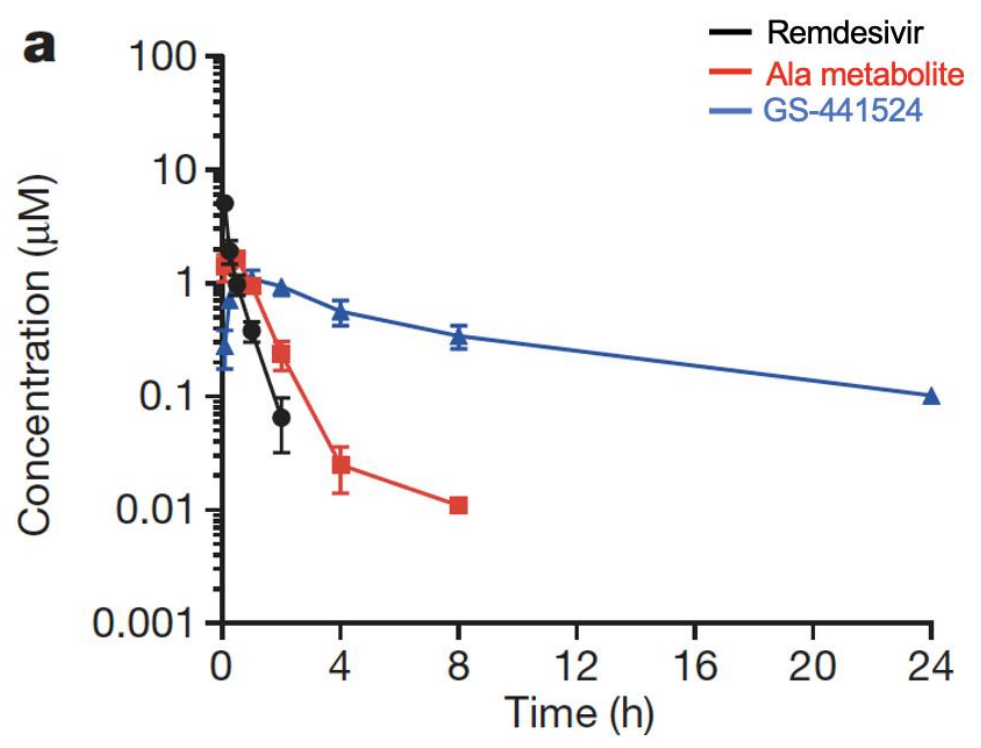

A3: Detection of the cell-impermeable intermediate Ala metabolite (red trace) in all preclinical PK studies indicates that the GS-441524 present in serum arises from premature extracellular hydrolysis of RDV: RDV $\rightarrow$ impermeable Ala metabolite $\rightarrow$ GS-441524. Above: Figure 2a in Warren et al. Nature (2016) ${ }^{9}$.

Q4: How do you explain the ability for RDV to generate higher levels of active NTP in peripheral blood mononuclear cells (PBMCs) compared to RDV over 72 hours (Below: Figure $1 \mathrm{~b}$ in Warren et al. Nature 2016)?

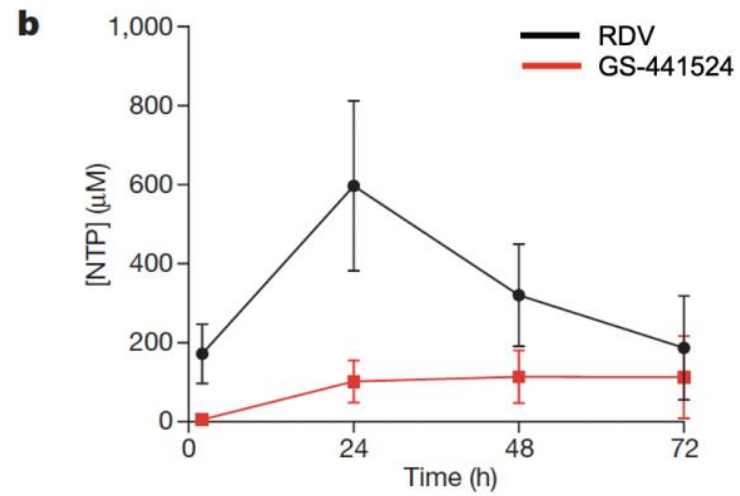

NTP formation in human monocyte-derived macrophages following 72-h incubation with $1 \mu \mathrm{M}$ GS-5734 (black) or GS441524 (red); mean \pm s.d., from 3 donors.

A4: First, this study was conducted in vitro, in the absence of serum esterases/phosphatases that jeopardize the stability of the RDV phosphate prodrug. Continuous $24 \mathrm{hr}+$ exposure to RDV is unphysiological, since RDV disappears from circulation within $1 \mathrm{hr}$. The appropriate comparison 
would be $1 \mathrm{~h}$ exposure for RDV vs $24 \mathrm{~h}$ exposure to GS-441524. A study by Wang and colleagues examined the differences in antiviral activity under continuous versus pulsed RDV treatment. In contrast to continuous treatment with RDV, pulsing for $3 \mathrm{~h}$ resulted in no inhibition of viral replication compared to continuous treatment (Below: Figure 1c, green bar in Wang et al. Cell Res, 202033). Second, NTP quantification was conducted in PBMCs (myeloid cells), which have high expression of CES1/CTSA and are thus a poor representation of the prodrug bioactivating enzyme expression pattern found in AT1/2 cells (see Section 3.3, 4.3). A more realistic NTP formation comparison would be in red blood cells, which do not express atypically high levels of CES1/CTSA and more closely reflect AT1/AT2 cells.

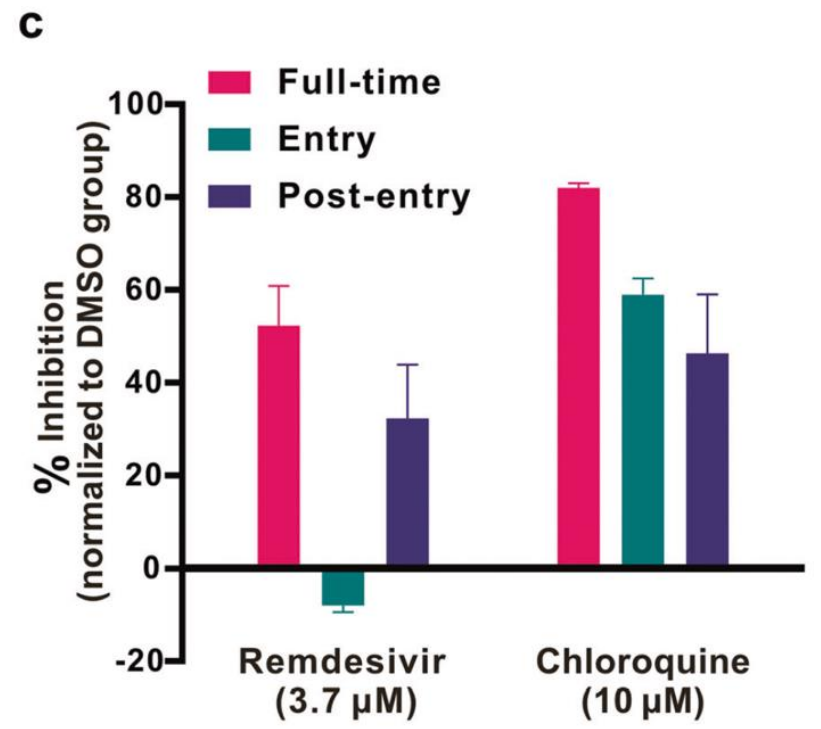

Fig. 1 The antiviral activities of the test drugs against 2019-nCoV in vitro. a Vero E6 cells were infected with 2019-nCoV at an MOI of 0.05 in the treatment of different doses of the indicated antivirals for $48 \mathrm{~h}$. The viral yield in the cell supernatant was then quantified by qRT-PCR. Cytotoxicity of these drugs to Vero E6 cells was measured by CCK-8 assays. The left and right $Y$-axis of the graphs represent mean \% inhibition of virus yield and cytotoxicity of the drugs, respectively. The experiments were done in triplicates. $\mathbf{b}$ Immunofluorescence microscopy of virus infection upon treatment of remdesivir and chloroquine. Virus infection and drug treatment were performed as mentioned above. At $48 \mathrm{~h}$ p.i., the infected cells were fixed, and then probed with rabbit sera against the NP of a bat SARS-related CoV ${ }^{2}$ as the primary antibody and Alexa 488-labeled goat anti-rabbit IgG (1:500; Abcam) as the secondary antibody, respectively. The nuclei were stained with Hoechst dye. Bars, $100 \mu \mathrm{m}$. c and d Time-of-addition experiment of remdesivir and chloroquine. For "Full-time" treatment, Vero E6 cells were pre-treated with the drugs for $1 \mathrm{~h}$, and virus was then added to allow attachment for $2 \mathrm{~h}$. Afterwards, the virus-drug mixture was removed, and the cells were cultured with drug-containing medium until the end of the experiment. For "Entry" treatment, the drugs were added to the cells for $1 \mathrm{~h}$ before viral attachment, and at $2 \mathrm{~h}$ p.i., the virus-drug mixture was replaced with fresh culture medium and maintained till the end of the experiment. For "Post-entry" experiment, drugs were added at $2 \mathrm{~h}$ p.i., and maintained until the end of the experiment. For all the experimental groups, cells were infected with $2019-\mathrm{nCOV}$ at an MOI of 0.05 , and virus yield in the infected cell supernatants was quantified by qRT-PCR c and NP expression in infected cells was analyzed by Western blot $\mathbf{d}$ at $14 \mathrm{~h}$ p.i.

\section{Q5: Previous cell culture studies with viruses other than SARS-CoV-2 show RDV as significantly more potent than GS-441524.}

A5: The most relevant cell culture data are provided in the recent publication by Pruijssers and colleagues $^{10}$; here, GS-441524 shows similar or superior potency to RDV against SARS-CoV-2infected cells. 
With regards to previous studies demonstrating greater potency with RDV over GS-441524 (Lo et al. Sci. Rep. 201712, Warren et al. Nature 2016 ${ }^{9}$ ) in a range of viruses, it should be noted that the design of these in vitro experiments poorly reflects the PK reality for RDV in vivo. All cell culture experiments conducted with GS-441524 and RDV have compared potencies of both drugs when exposed for the same duration, typically over 24-48 h or longer. This assumes that both that the target cells are exposed to either drug for the same duration in vivo, which is demonstrably false. The short half-life of RDV in plasma and persistence of GS-441524 is not accounted for in these cell culture experiments. A more accurate in vitro model of the in vivo PK situation would be to compare the antiviral activities of RDV and GS-441524 when cells are exposed for the same duration as the plasma persistence in vivo ( $\sim 1 \mathrm{~h}$ for RDV versus $\sim 24 \mathrm{~h}$ for GS-441524). Amidst the design oversight of these in vitro experiments, it is even more impressive that GS-441524 exerts similar or superior potency compared to RDV in the Pruijssers study ${ }^{10}$ given that greater-than-24-hour exposure to RDV simply does not occur in vivo.

\section{Q6: How do you know that the antiviral activity by RDV is not achieve by the short $1 \mathrm{~h}$ exposure when it is still intact and in circulation?}

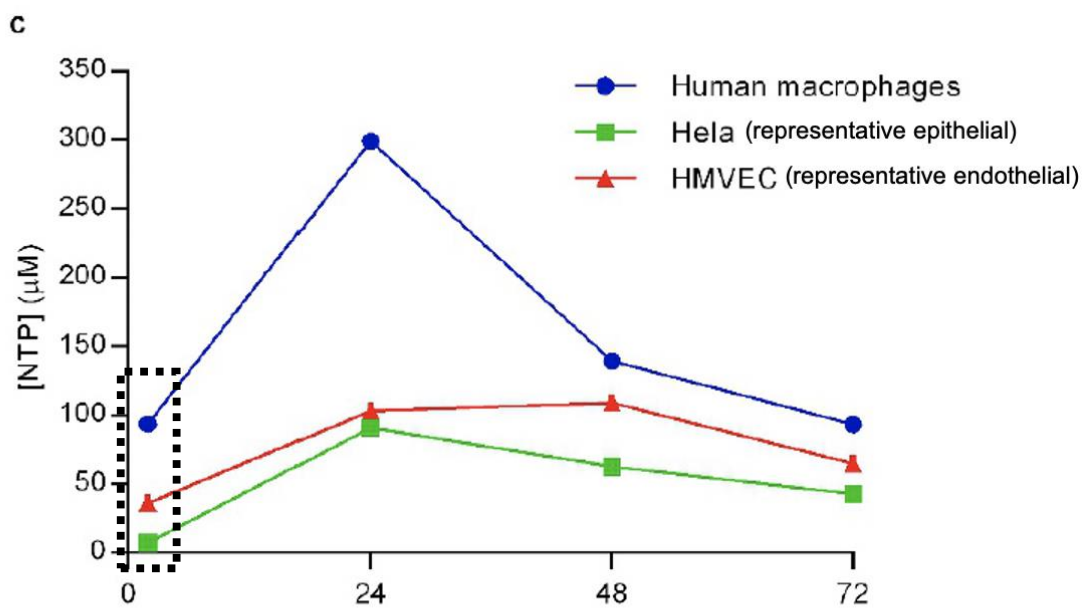

"The mixture of GS-5734 and its diastereomer on phosphorous was incubated continuously for $72 \mathrm{~h}$ at $1 \mu \mathrm{M}$ and levels of intracellular NTP were determined (results are the average of duplicate incubations performed in each cell type; two independent studies were performed in HMVEC isolated from different donors)."

A6: (Above: Extended Data Figure 1c from Warren et al. Nature 2016 ${ }^{9}$ AT1/2 cells are the main target population for SARS-CoV-2 replication. For antiviral activity to occur within $1 \mathrm{~h}$ in AT1/2 cells, high levels active NTP would have be produced by RDV (See Section 4.3). Given the exceedingly low expression of RDV bioactivating enzymes (CES1/CTSA) in AT1/2 cells (See Section 3.3), it is highly unlikely that bioactivation to the active NTP at sufficiently high levels to meet or surpass EC50 values documented in the Pruijssers study ${ }^{10}$ would occur. In contrast, cells and tissues with high expression of CES1/CTSA such as the liver and PBMCs are capable of extracting and generating active NTP within the $1 \mathrm{~h}$ timeframe, which coincides with the presence McGuigan prodrug moieties on Sofosbuvir ${ }^{38}$ and the initial development of RDV for the treatment of hepatitis ${ }^{7}$. This hypothesis 
is supported by data produced by Warren and colleagues (Extended Data Figure 1) ${ }^{9}$, demonstrating rapid formation of active NTP in PBMCs $(\sim 100 \mu \mathrm{M}$ at $2 \mathrm{~h}$, dashed box $)$ but dramatically slower formation of NTP in representative epithelial ( $\sim 2 \mu \mathrm{M}$ at $2 \mathrm{hrs}$, HeLa green) and endothelial (HMVEC) cells. Again, it should be noted that this comparison was conducted in vitro with continuous dosing and also lacks serum esterases/phosphatases that can hydrolyze the RDV phosphate prodrug.

\section{Q7: You cited liver toxicities observed in the recent case report in Covid-19 patients treated with RDV $^{39}$. How do you know that this isn't just an anecdotal observation?}

A7: Gilead has confirmed to us (VCY, FLM) that liver toxicity is an issue with RDV. This was also confirmed to us by Dr. John Beigel ${ }^{13}$, who is the first author on preliminary report on RDV in the NIH-sponsored randomized controlled trial in severe Covid-19 patients: "Re increasing the dose this was tried in healthy volunteers, and they had more LFT abnormalities. Gilead would have the data, I just remember seeing this in a presentation about remdesivir" (JB to VCY). Additionally, the potential for liver and kidney injury has been documented in the emergency use authorization (EUA) document for RDV60,61.

Q8: If GS-441524 is so exceptional at treating FIP, then why is it not approved for veterinary use?

A8: Niels Pedersen, the veterinary researcher whose group has conducted most of studies with GS441524 in cats, has discussed Gilead's unwillingness to license the drug for veterinary use at length in a recently published article in The Atlantic by Sarah Zhang52. In private correspondences with Pedersen, he has said "The truth is that Gilead has totally committed to Remdesivir and they have gotten themselves into a track that cannot be easily exited. Starting over with GS-441524 would be a bad choice under these circumstances and would erase all of the movement toward full licensing of Remdesivir." 
Q9: Does GS-441524 simply work better in cat cells against cat coronavirus compared to the human situation?
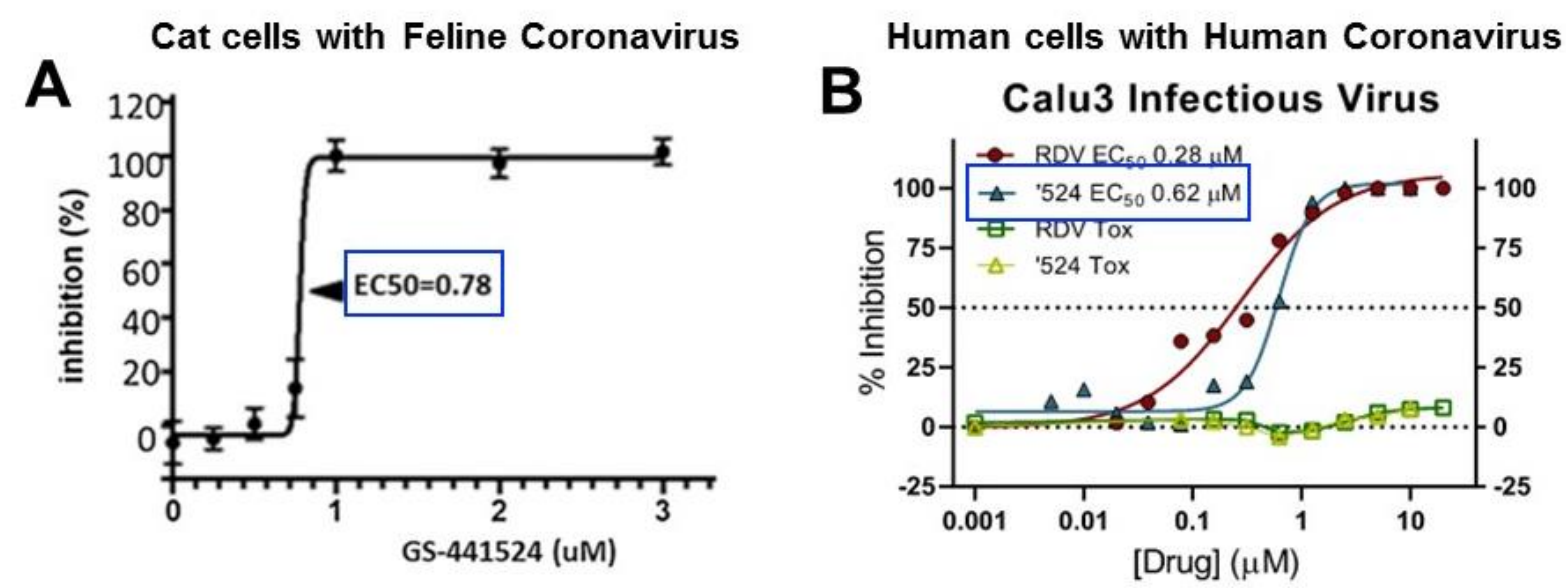

A9: No data supports the notion that GS-441524 is unusually effective in cat cells. After corresponding with other journalists and scientists, it appears that this is a message that Gilead has been perpetuating. The $\mathrm{EC}_{50}$ for GS-441524 against FCov-infected cat cells is $\sim 0.8 \mu \mathrm{M}$ (A, blue box from Figure 1c in Murphy et al. Vet. Microbiol. 2018), which is nearly the same as the $\mathrm{EC}_{50}$ for SARSCoV-2 in human cells (B, $0.62 \mu \mathrm{M}$ in Calu3 cells, blue box from Figure $2 d$ in Pruijssers et al. Cell Rep. 2020).

Q10: Unpublished reports from Gilead purport that the oral bioavailability of GS-441524 is low (i.e. that only a small fraction of the drug administered as a pill would get absorbed from the intestines and reach circulation).

A10: While we have not seen these unpublished data ourselves, Gilead shared that the oral bioavailability of GS-441524 in monkey is around 5\% (a "good" drug would be $\sim 15-30 \%$ or higher ${ }^{62}$ ). First, extrapolating oral bioavailability from animals is an imperfect science and unless directly tested in human patients, the true oral bioavailability is unknown. Nevertheless, low oral bioavailability can be compensated for by higher drug administration, provided there are no intestinal reactions. Even when administered at the highest doses, none of the monkey studies have suggested that intestinal reactions occur with GS-44152429. Additionally, cats with FIP have been treated with oral dosing of GS-44152453,54, suggesting that higher doses can compensate for low oral bioavailability. In addition, the long biological half-life of GS-441524 in humans ( $>24 \mathrm{~h}$ ) suggests that multi-day dosing (e.g. morning, noon, night) could be used to bioaccumulate GS441524. Indeed, bioaccumulation of GS-441524 ( 1.9-fold) was already found during a phase I, dose-escalation study with IV administration of RDV27.

Additional questions? Email: yan22v@mtholyoke.edu (VCY) or fmuller@mdanderson.org (FLM) 


\section{References}

(1) Mason, R. J. Pathogenesis of COVID-19 from a Cell Biology Perspective. European Respiratory Journal. European Respiratory Society April 1, 2020.

(2) Martines, R. B.; Ritter, J. M.; Matkovic, E.; Gary, J.; Bollweg, B. C.; Bullock, H.; Goldsmith, C. S.; Silva-Flannery, L.; Seixas, J. N.; Reagan-Steiner, S.; et al. Pathology and Pathogenesis of SARSCoV-2 Associated with Fatal Coronavirus Disease, United States. Emerg. Infect. Dis. 2020, 26 (9).

(3) Yao, X. H.; He, Z. C.; Li, T. Y.; Zhang, H. R.; Wang, Y.; Mou, H.; Guo, Q.; Yu, S. C.; Ding, Y.; Liu, X.; et al. Pathological Evidence for Residual SARS-CoV-2 in Pulmonary Tissues of a Ready-forDischarge Patient. Cell Research. Springer Nature June 1, 2020, pp 541-543.

(4) Carsana, L.; Sonzogni, A.; Nasr, A.; Rossi, R. S.; Pellegrinelli, A.; Zerbi, P.; Rech, R.; Colombo, R.; Antinori, S.; Corbellino, M.; et al. Pulmonary Post-Mortem Findings in a Series of COVID19 Cases from Northern Italy: A Two-Centre Descriptive Study. Lancet Infect. Dis. 2020, 0 (0).

(5) Hoffmann, M.; Kleine-Weber, H.; Schroeder, S.; Krüger, N.; Herrler, T.; Erichsen, S.; Schiergens, T. S.; Herrler, G.; Wu, N. H.; Nitsche, A.; et al. SARS-CoV-2 Cell Entry Depends on ACE2 and TMPRSS2 and Is Blocked by a Clinically Proven Protease Inhibitor. Cell 2020, 181 (2), 271-280.e8.

(6) Gupta, A.; Madhavan, M. V; Sehgal, K. $\square$. Extrapulmonary Manifestations of COVID-19.

(7) Butler, T.; Cho, A.; Kim, C.; Saunders, O. L.; Zhang, L. 1' -SUBSTITUTED CARBA-NUCLEOSIDE ANALOGS FOR ANTIVIRAL TREATMENT . WO2009132135, October 29, 2009.

(8) Siegel, D.; Hui, H. C.; Doerffler, E.; Clarke, M. O.; Chun, K.; Zhang, L.; Neville, S.; Carra, E.; Lew, W.; Ross, B.; et al. Discovery and Synthesis of a Phosphoramidate Prodrug of a Pyrrolo[2,1$f]$ [Triazin-4-Amino] Adenine $C$-Nucleoside (GS-5734) for the Treatment of Ebola and Emerging Viruses. J. Med. Chem. 2017, 60 (5), 1648-1661.

(9) Warren, T. K.; Jordan, R.; Lo, M. K.; Ray, A. S.; Mackman, R. L.; Soloveva, V.; Siegel, D.; Perron, M.; Bannister, R.; Hui, H. C.; et al. Therapeutic Efficacy of the Small Molecule GS-5734 against Ebola Virus in Rhesus Monkeys. Nature 2016, 531 (7594), 381-385.

(10) Pruijssers, A. J.; George, A. S.; Schä, A.; Baric, R. S.; Denison, M. R.; Sheahan, T. P. Remdesivir Inhibits SARS-CoV-2 in Human Lung Cells and Chimeric SARS-CoV Expressing the SARSCoV-2 RNA Polymerase in Mice. Cell Rep. 2020, 107940.

(11) Williamson, B. N.; Feldmann, F.; Schwarz, B.; Meade-White, K.; Porter, D. P.; Schulz, J.; Van Doremalen, N.; Leighton, I.; Yinda, C. K.; Pérez-Pérez, L.; et al. Clinical Benefit of Remdesivir in Rhesus Macaques Infected with SARS-CoV-2. Nature 2020.

(12) Lo, M. K.; Jordan, R.; Arvey, A.; Sudhamsu, J.; Shrivastava-Ranjan, P.; Hotard, A. L.; Flint, M.; McMullan, L. K.; Siegel, D.; Clarke, M. O.; et al. GS-5734 and Its Parent Nucleoside Analog Inhibit Filo-, Pneumo-, and Paramyxoviruses. Sci. Rep. 2017, 7 (1), 43395.

(13) Beigel, J. H.; Tomashek, K. M.; Dodd, L. E.; Mehta, A. K.; Zingman, B. S.; Kalil, A. C.; Hohmann, E.; Chu, H. Y.; Luetkemeyer, A.; Kline, S.; et al. Remdesivir for the Treatment of Covid-19Preliminary Report. N. Engl. J. Med. 2020, NEJMoa2007764.

(14) Wang, Y.; Zhang, D.; Du, G.; Du, R.; Zhao, J.; Jin, Y.; Fu, S.; Gao, L.; Cheng, Z.; Lu, Q.; et al. Remdesivir in Adults with Severe COVID-19: A Randomised, Double-Blind, PlaceboControlled, Multicentre Trial. Lancet 2020, 395 (10236), 1569-1578.

(15) de Wit, E.; Feldmann, F.; Cronin, J.; Jordan, R.; Okumura, A.; Thomas, T.; Scott, D.; Cihlar, T.; Feldmann, H. Prophylactic and Therapeutic Remdesivir (GS-5734) Treatment in the Rhesus 
Macaque Model of MERS-CoV Infection. Proc. Natl. Acad. Sci. 2020.

(16) Sheahan, T. P.; Sims, A. C.; Graham, R. L.; Menachery, V. D.; Gralinski, L. E.; Case, J. B.; Leist, S. R.; Pyrc, K.; Feng, J. Y.; Trantcheva, I.; et al. Broad-Spectrum Antiviral GS-5734 Inhibits Both Epidemic and Zoonotic Coronaviruses. Sci. Transl. Med. 2017, 9 (eaal3653).

(17) Siegel, D.; Hui, H. C.; Doerffler, E.; Clarke, M. O.; Chun, K.; Zhang, L.; Neville, S.; Carra, E.; Lew, W.; Ross, B.; et al. Discovery and Synthesis of a Phosphoramidate Prodrug of a Pyrrolo[2,1$f$ ] [Triazin-4-Amino] Adenine $C$-Nucleoside (GS-5734) for the Treatment of Ebola and Emerging Viruses. J. Med. Chem. 2017, 60 (5), 1648-1661.

(18) Clarke, M. O. N. H.; Feng, J. Y.; Jordan, R.; Mackman, R. L.; Ray, A. S.; Siegel, D. METHODS FOR TREATING ARENAVIRIDAE AND CORONAVIRIDAE VIRUS INFECTIONS. US 2017/0071964A1, March 16, 2017.

(19) Alanazi, A. S.; James, E.; Mehellou, Y. The ProTide Prodrug Technology: Where Next? ACS Med. Chem. Lett. 2019, 10 (1), 2-5.

(20) Jarvis, L. M. Scaling up Remdesivir amid the Coronavirus Crisis. C\&EN. April 20, 2020.

(21) Gilead's Investigational Antiviral Remdesivir Receives U.S. Food and Drug Administration Emergency Use Authorization for the Treatment of COVID-19 https://www.gilead.com/news-and-press/press-room/press-releases/2020/5/gileadsinvestigational-antiviral-remdesivir-receives-us-food-and-drug-administration-emergencyuse-authorization-for-the-treatment-of-covid19 (accessed May 7, 2020).

(22) Herper, M. Gilead CEO: We're Going to Make Sure Remdesivir Is Accessible. STAT. April 29, 2020.

(23) Wise, J. Remdesivir: US Purchase of World Stocks Sparks New “Hunger Games," Warn Observers. BMJ 2020, 370, m2661.

(24) Remdesivir Distribution Causes Confusion, Leaves Some Hospitals Empty-Handed. NPR. May $14,2020$.

(25) Trump Administration Secures New Supplies of Remdesivir for the United States | HHS.gov https://www.hhs.gov/about/news/2020/06/29/trump-administration-secures-newsupplies-remdesivir-united-states.html (accessed Jul 14, 2020).

(26) Tempestilli, M.; Caputi, P.; Avataneo, V.; Notari, S.; Forini, O.; Scorzolini, L.; Marchioni, L.; Bartoli, T. A.; Castilletti, C.; Lalle, E.; et al. Pharmacokinetics of Remdesivir and GS-441524 in Two Critically Ill Patients Who Recovered from COVID-19. J. Antimicrob. Chemother. 2020, dkaa239, 1-4.

(27) Humeniuk, R.; Mathias, A.; Cao, H.; Osinusi, A.; Shen, G.; Chng, E.; Ling, J.; Vu, A.; German, P. Safety, Tolerability, and Pharmacokinetics of Remdesivir, An Antiviral for Treatment of COVID-19, in Healthy Subjects. Clin. Transl. Sci. 2020, cts.12840.

(28) Alvarez, J. C.; Moine, P.; Etting, I.; Annane, D.; Larabi, I. A. Quantification of Plasma Remdesivir and Its Metabolite GS-441524 Using Liquid Chromatography Coupled to Tandem Mass Spectrometry. Application to a Covid-19 Treated Patient. Clin. Chem. Lab. Med. 2020.

(29) Remdesivir: Summary on Compassionate Use EMA/178637/2020 - Rev. 1; 2020.

(30) Akinci, E.; Cha, M.; Lin, L.; Yeo, G.; Hamilton, M. C.; Donahue, C. J.; Bermudez-Cabrera, H. C.; Zanetti, L. C.; Chen, M.; Barkal, S. A.; et al. Elucidation of Remdesivir Cytotoxicity Pathways through Genome-Wide CRISPR-Cas9 Screening and Transcriptomics. bioRxiv 2020, 2020.08.27.270819.

(31) Murakami, E.; Wang, T.; Babusis, D.; Lepist, E.-I.; Sauer, D.; Park, Y.; Vela, J. E.; Shih, R.; Birkus, G.; Stefanidis, D.; et al. Metabolism and Pharmacokinetics of the Anti-Hepatitis C Virus 
Nucleotide Prodrug GS-6620. Antimicrob. Agents Chemother. 2014, 58, 1943-1951.

(32) Yan, V. C.; Muller, F. L. Advantages of the Parent Nucleoside GS-441524 over Remdesivir for Covid-19 Treatment. ACS Med. Chem. Lett. 2020, 11 (7), 1361-1366.

(33) Wang, M.; Cao, R.; Zhang, L.; Yang, X.; Liu, J.; Xu, M.; Shi, Z.; Hu, Z.; Zhong, W.; Xiao, G. Remdesivir and Chloroquine Effectively Inhibit the Recently Emerged Novel Coronavirus (2019-NCoV) in Vitro. Cell Research. Springer Nature March 1, 2020, pp 269-271. Guo, D.; Zhu, Q.; Zhang, H.; Sun, D. Proteomic Analysis of Membrane Proteins of Vero Cells: Exploration of Potential Proteins Responsible for Virus Entry. DNA Cell Biol. 2014, 33 (1), 20-28.

Mumtaz, N.; Jimmerson, L. C.; Bushman, L. R.; Kiser, J. J.; Aron, G.; Reusken, C. B. E. M.; Koopmans, M. P. G.; van Kampen, J. J. A. Cell-Line Dependent Antiviral Activity of Sofosbuvir against Zika Virus. Antiviral Res. 2017, 146, 161-163.

(36) Schaefer, I.-M.; Padera, R. F.; Solomon, I. H.; Kanjilal, S.; Hammer, M. M.; Hornick, J. L.; Sholl, L. M. In Situ Detection of SARS-CoV-2 in Lungs and Airways of Patients with COVID-19. Mod. Pathol. 2020, 1-11.

(37) Cho, A.; Saunders, O. L.; Butler, T.; Zhang, L.; Xu, J.; Vela, J. E.; Feng, J. Y.; Ray, A. S.; Kim, C. U. Synthesis and Antiviral Activity of a Series of 1'-Substituted 4-Aza-7,9-Dideazaadenosine CNucleosides. Bioorg. Med. Chem. Lett. 2012, 22 (8), 2705-2707.

Bhatia, H. K.; Singh, H.; Grewal, N.; Natt, N. K. Sofosbuvir: A Novel Treatment Option for Chronic Hepatitis C Infection. J. Pharmacol. Pharmacother. 2014, 5 (4), 278.

Dubert, M.; Visseaux, B.; Isernia, V.; Bouadma, L.; Deconinck, L.; Patrier, J.; Wicky, P.-H.; Le Pluart, D.; Kramer, L.; Rioux, C.; et al. Case Reports Study of the First Five Patients COVID-19 Treated with Remdesivir in France. Int. J. Infect. Dis. 2020.

(40) Fan, Q.; Zhang, B.; Ma, J.; Zhang, S. Safety Profile of the Antiviral Drug Remdesivir: An Update. Biomedicine and Pharmacotherapy. Elsevier Masson SAS October 1, 2020, p 110532.

(41) Wichmann, D.; Sperhake, J.-P.; Lütgehetmann, M.; Steurer, S.; Edler, C.; Heinemann, A.; Heinrich, F.; Mushumba, H.; Kniep, I.; Schröder, A. S.; et al. Autopsy Findings and Venous Thromboembolism in Patients With COVID-19. Ann. Intern. Med. 2020, pp: M20-2003. O’Day, D. An Open Letter from Daniel O'Day, Chairman \&amp; CEO, Gilead Sciences https://stories.gilead.com//articles/an-open-letter-from-daniel-oday-june-22 (accessed Jul 1, 2020).

(43) Stella, V.; He, Q. Cyclodextrins. Toxicol. Pathol. 2008, 36, 36-42.

(44) Friman, T.; Chernobrovkin, A.; Martinez Molina, D.; Arnold, L. CETSA ® MS Profiling for a Comparative Assessment of FDA Approved Antivirals Repurposed for COVID-19 Therapy Identifies Trip13 as a Remdesivir off-Target. bioRxiv 2020, 2020.07.19.210492.

(45) Addie, D.; Belák, S.; Boucraut-Baralon, C.; Egberink, H.; Frymus, T.; Gruffydd-Jones, T.; Hartmann, K.; Hosie, M. J.; Lloret, A.; Lutz, H.; et al. Feline Infectious Peritonitis. ABCD Guidelines on Prevention and Management. J. Feline Med. Surg. 2009, 11 (7), 594-604.

(46) Glansbeek, H. L.; Haagmans, B. L.; Te Lintelo, E. G.; Egberink, H. F.; Duquesne, V.; Aubert, A.; Horzinek, M. C.; Rottier, P. J. M. Adverse Effects of Feline IL-12 during DNA Vaccination against Feline Infectious Peritonitis Virus. J. Gen. Virol. 2002, 83 (1), 1-10. Pedersen, N. C.; Perron, M.; Bannasch, M.; Montgomery, E.; Murakami, E.; Liepnieks, M.; Liu, H. Efficacy and Safety of the Nucleoside Analog GS-441524 for Treatment of Cats with Naturally Occurring Feline Infectious Peritoniti. J. Feline Med. Surg. 2019, 21 (4), 271-281.

(48) Murphy, B. G.; Perron, M.; Murakami, E.; Bauer, K.; Park, Y.; Eckstrand, C.; Liepnieks, M.; Pedersen, N. C. The Nucleoside Analog GS-441524 Strongly Inhibits Feline 
Infectiousperitonitis (FIP) Virus in Tissue Culture and Experimental Cat Infection Studies. Vet. Microbiol. 2018, 219, 226-233.

(49) Song, E.; Zhang, C.; Israelow, B.; Lu, P.; Weizman, O.-E.; Liu, F.; Dai, Y.; Szigeti-Buck, K.; Yasumoto, Y.; Wang, G.; et al. Neuroinvasive Potential of SARS-CoV-2 Revealed in a Human Brain Organoid Model. bioRxiv 2020, 2020.06.25.169946.

(50) Dickinson, P. J.; Bannasch, M.; Thomasy, S. M.; Murthy, V. D.; Vernau, K. M.; Liepnieks, M.; Montgomery, E.; Knickelbein, K. E.; Murphy, B.; Pedersen, N. C. Antiviral Treatment Using the Adenosine Nucleoside Analogue GS -441524 in Cats with Clinically Diagnosed Neurological Feline Infectious Peritonitis. J. Vet. Intern. Med. 2020, jvim.15780.

(51) Sheahan, T. P.; Sims, A. C.; Graham, R. L.; Menachery, V. D.; Gralinski, L. E.; Case, J. B.; Leist, S. R.; Pyrc, K.; Feng, J. Y.; Trantcheva, I.; et al. Broad-Spectrum Antiviral GS-5734 Inhibits Both Epidemic and Zoonotic Coronaviruses. Sci. Transl. Med. 2017, 9 (396).

(52) Zhang, S. The Strange Tale of Remdesivir and a Black-Market Cat Drug - The Atlantic. The Atlantic. May 8, 2020.

(53) Pedersen, N. C. Inappropriate Use of GS-441524 in an Attempt to Eliminate Feline Enteric Coronavirus (FECV) from Healthy Cats.

(54) Addie, D. D.; Curran, S.; Bellini, F.; Crowe, B.; Sheehan, E.; Ukrainchuk, L.; Decaro, N. Oral Mutian®X Stopped Faecal Feline Coronavirus Shedding by Naturally Infected Cats. Res. Vet. Sci. 2020, 130, 222-229.

(55) Musther, H.; Olivares-Morales, A.; Hatley, O. J. D.; Liu, B.; Rostami Hodjegan, A. Animal versus Human Oral Drug Bioavailability: Do They Correlate? Eur. J. Pharm. Sci. 2014, 57 (1), 280291.

(56) Wang, T.; Babusis, D.; Park, Y.; Niu, C.; Kim, C.; Zhao, X.; Lu, B.; Ma, B.; Muench, R. C.; Sperger, D.; et al. Species Differences in Liver Accumulation and Metabolism of Nucleotide Prodrug Sofosbuvir. Drug Metab. Pharmacokinet. 2020, 35 (3), 334-340.

(57) Paxton, L. A.; Hope, T.; Jaffe, H. W. Pre-Exposure Prophylaxis for HIV Infection: What If It Works? Lancet 2007, 370 (9581), 89-93.

(58) Grant, R. M.; Lama, J. R.; Anderson, P. L.; McMahan, V.; Liu, A. Y.; Vargas, L.; Goicochea, P.; Casapía, M.; Guanira-Carranza, J. V.; Ramirez-Cardich, M. E.; et al. Preexposure Chemoprophylaxis for HIV Prevention in Men Who Have Sex with Men. N. Engl. J. Med. 2010, 363 (27), 2587-2599.

(59) Baeten, J. M.; Donnell, D.; Ndase, P.; Mugo, N. R.; Campbell, J. D.; Wangisi, J.; Tappero, J. W.; Bukusi, E. A.; Cohen, C. R.; Katabira, E.; et al. Antiretroviral Prophylaxis for HIV Prevention in Heterosexual Men and Women. N. Engl. J. Med. 2012, 367 (5), 399-410.

(60) FACT SHEET FOR HEALTH CARE PROVIDERS EMERGENCY USE AUTHORIZATION (EUA) OF VEKLURY ® (Remdesivir).

(61) Gilead's Investigational Antiviral Veklury® (Remdesivir) Receives U.S. Food and Drug Administration Emergency Use Authorization for the Treatment of Patients With Moderate COVID-19 https://www.gilead.com/news-and-press/press-room/pressreleases/2020/8/gileads-investigational-antiviral-veklury-remdesivir-receives-us-foodand-drug-administration-emergency-use-authorization-for-the-treatment-of-p?spredfasttrk-id=sf127825419\&spredfast-trk-id=sf127872134 (accessed Aug 29, 2020).

(62) Lee, W. A.; He, G.-X.; Eisenberg, E.; Cihlar, T.; Swaminathan, S.; Mulato, A.; Cundy, K. C. Selective Intracellular Activation of a Novel Prodrug of the Human Immunodeficiency Virus Reverse Transcriptase Inhibitor Tenofovir Leads to Preferential Distribution and Accumulation in Lymphatic Tissue. Antimicrob. Agents Chemother. 2005, 49 (5), 1898-1906. 
(63) Cohen, E.; Azad, A. The US Government's Supply of Covid-19 Drug Remdesivir Runs out at the End of the Month. CNN. June 8, 2020. 